Document downloaded from:

http://hdl.handle.net/10251/154393

This paper must be cited as:

Xuan, T.; Desantes J.M.; Pastor, JV.; García-Oliver, JM. (2019). Soot temperature characterization of spray a flames by combined extinction and radiation methodology.

Combustion and Flame. 204:290-303. https://doi.org/10.1016/j.combustflame.2019.03.023

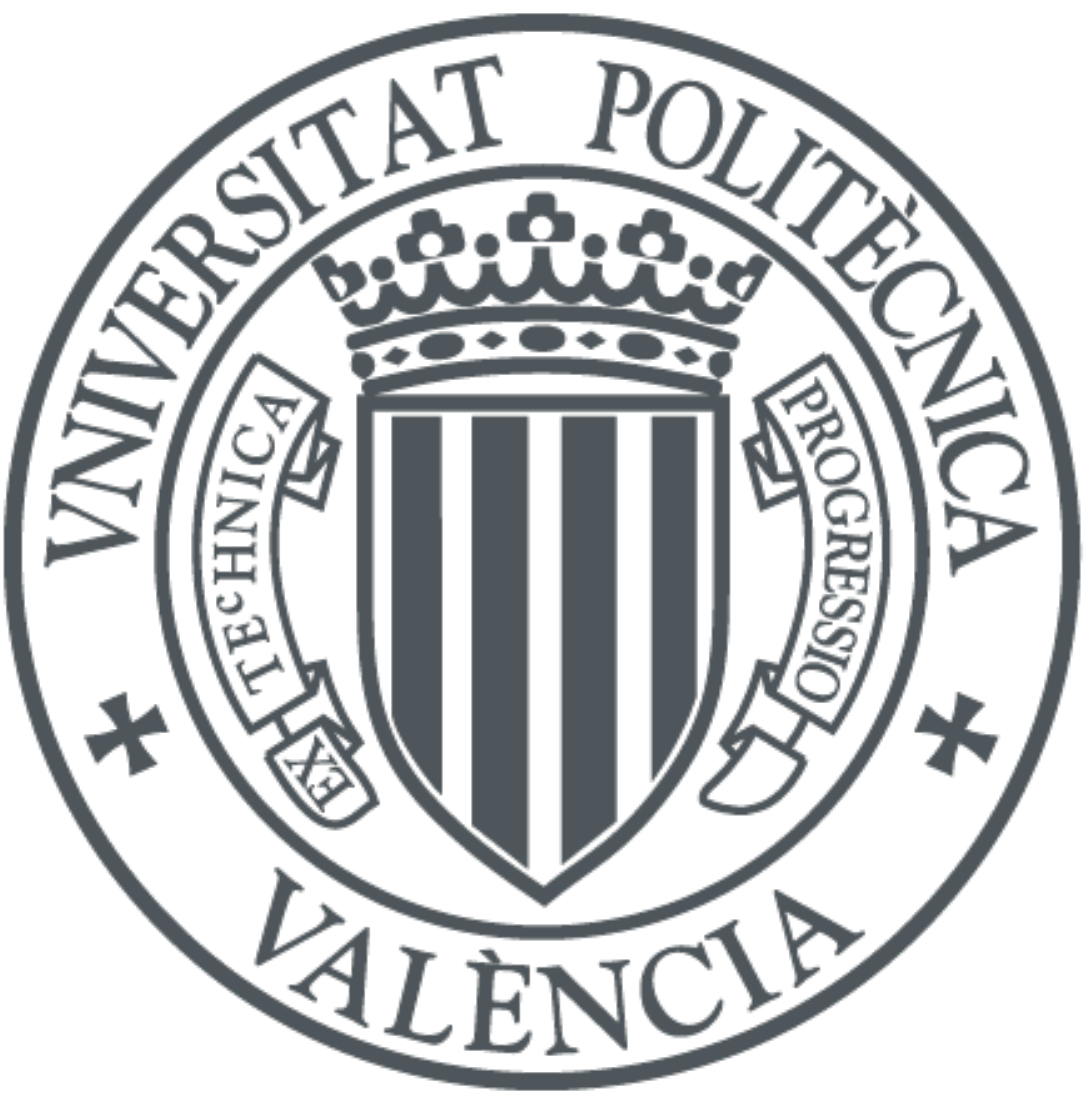

The final publication is available at

https://doi.org/10.1016/j.combustflame.2019.03.023

Copyright Elsevier

Additional Information 


\title{
Soot Temperature Characterization of Spray A Flames by Combined Extinction and Radiation Methodology ${ }^{1}$
}

\author{
Tiemin Xuan ${ }^{1,3}$, Jose M. Desantes², Jose V. Pastor² , Jose M. García-Oliver² \\ 1 School of Energy and Power Engineering, Jiangsu University, Zhenjiang 212013, China \\ 2 CMT-Motores Térmicos, Universitat Politècnica de València, Valencia 46022, Spain \\ 3 CSSC Marine Power Co, LTD, Zhenjiang 212002, China
}

\begin{abstract}
Even though different optical techniques have been applied on 'Spray A' in-flame soot quantification within Engine Combustion Network in recent years, little information can be found for soot temperature measurement. In this study, a combined extinction and radiation methodology has been developed with different wavelengths and applied on quasi-steady Diesel flame to obtain the soot amount and temperature distribution simultaneously by considering self-absorption issues. All the measurements were conducted in a constant pressure combustion chamber. The fuel as well as the operating conditions and the injector used were chosen following the guidelines of the Engine Combustion Network. Uncertainty caused by wavelength selection was evaluated. Additionally, temperature-equivalence ratio maps were constructed by combining the measurements with a $1 \mathrm{D}$ spray model.
\end{abstract}

Temperature fields during the quasi-steady combustion phase show peak temperatures around the limit of the radiation field, in agreement with a typical diffusion flame structure. Effects of different operating parameters on soot formation and temperature were investigated. Soot temperature increases dramatically with oxygen concentration, but it shows much less sensitivity with ambient temperature and injection pressure, which on the other hand have significant effects on soot production.

\section{Introduction}

Soot produced during the diesel engine combustion process has been acknowledge to have negative impacts on human health and environment. Faced with the challenge of meeting stringent emissions regulations, detailed understanding and capability for accurate prediction of in-flame soot processes are necessary. However, because of the high complexity of the numerous physical phenomena and chemical kinetic mechanisms involved, knowledge of in-flame soot is still limited and it is still a big challenge for computational fluid dynamics (CFD) simulation to get a good quantification on soot amount [1].

In recent years, optical diagnostics have been extensively applied in various environments to have a better understanding of the soot processes in diesel combustion. Based soot thermal radiation measurement, Two-color pyrometry $(2 \mathrm{C})$ has been developed to quantify the temporal and 2D spatial

\footnotetext{
${ }^{1}$ In memory of Jose Enrique Julia Bolivar, who started combustion visualization techniques at CMT, a very relevant researcher and a good friend, who passed away on January 19th 2018.
} 
evolution of the soot distribution and corresponding temperature [2][3][4][5] . However, because of signal self-absorption problems, large uncertainties exist on the soot optical thickness (KL), especially for highly sooting conditions[6]. Besides, the obtained soot temperature is also an assumed averaged temperature along the optical path [5]. Laser-induced incandescence (LII) is the other major soot diagnostics technique, which is able to qualitatively visualize the soot spatial distribution by recording soot radiation induced because of the absorption of laser energy [7][8][9] . However, due to hardware limitations of conventional LII measurement systems, usually only one image can be recorded for each injection, unless highly sophisticated laser sources and imaging systems are used [10]. Laser-Extinction Method (LEM) is one of the typical soot measurement techniques[11][12][13][14], which are based upon the extinction of light caused by absorption from the soot particles. A continuous point laser is used as the light source in this technique, which enables to measure the soot with a good time evolution, but it is spatially limited by the beam size[14]. With the improvement of high speed cameras and light sources, a two-dimensional Diffused Background-illumination (DBI) extinction imaging technique has been developed and applied within Engine Combustion Network (ECN)[15][16][17][18]. In the DBI setup, the light source is supplied by a bundle of diffused rays which are able to cover the whole flame, and a high-speed camera is applied in the collection section. Consequently, both good spatial and time resolution can be achieved[6].

The present work is within the framework of the Engine Combustion Network which is a worldwide group of research institutes that started a collaboration in order to provide high-quality data and consistent results for modeling purposes [19]. Although different optical diagnostics were carried out on diesel soot amount quantification within this group, limited information can be found for detailed soot temperature measurements. Skeen et al.[20] obtained soot temperature through an imaging spectrometer but only the axial values were presented. Bolla et al.[21] studied the effects of radiation heat transfer on 'Spray $A^{\prime}$ flame temperature and soot formation by means of CFD but further experimental validation still needs to be done.

The present paper aims at developing a combined extinction and radiation methodology to quantify the three-dimensional soot amount and temperature simultaneously by considering the selfabsorption effects. The interaction mechanism between soot amount and soot temperature under different operating conditions has been studied, and a detailed soot temperature database has been compiled for modeling validation. The experiments of this study were performed in a constant pressure flow facility (CPF) equipped with Spray $A$ injector under a nearly quiescent environment. In order to substantiate the analysis, a 1D spray model [22][23][24] has been applied.

\section{Methodology}

The present methodology measures simultaneously light extinction and thermal emission processes across the sooting flame. While the extinction depends only on soot distribution, thermal radiation also depends on temperature. Therefore, light extinction is used to derive the soot distribution within the flame. Once this is known, soot radiation is used to derive soot temperature. A similar methodology has been applied by Legro et al [25] to a steady laminar axis-symmetric non-premixed ethylene flame.

Both extinction and radiation measurements are based on integrated information along the line-ofsight optical path (projected data) and hence reconstruction methods are needed taking advantage of the spray axis-symmetry. The methodology divides the quasi-steady soot cloud into two parts along spray axis and assumes each half part is an axis-symmetric configuration, as shown in iError! No se encuentra el origen de la referencia.. Then, each part is processed following the same procedures. 
The propagation of the spectral radiation intensity $I(y)$ in a given direction along an optical pathway $y$ can be expressed as [26]:

$$
\frac{d I(y)}{d y}=k(y)\left[I_{b}(y)-I(y)\right]
$$

According to Planck's Law, $I_{b}$ is the spectral blackbody radiation intensity, which is a function of local temperature $\mathrm{T}$, as shown in Eq.(2).

$$
I_{b}(\lambda, T)=\frac{1}{\lambda^{5}} \cdot \frac{c_{1}}{\left[\exp \left(\frac{c_{2}}{\lambda T}\right)-1\right]}
$$

where $c_{1}$ and $c_{2}$ are constants, $c_{1}=1.1910439 \times 10^{-16} \mathrm{w} \mathrm{m}^{2} \mathrm{sr}^{-1}$ and $c_{2}=1.4388 \times 10^{-2} \mathrm{mk}$.

At a given wavelength $\lambda$, the overall radiation intensity $\left(I_{r}\right)$ obtained from projected line $S$ (as shown in iError! No se encuentra el origen de la referencia.) is a result of the integrated contribution of emitted radiation $\left(k I_{b}\right)$ and self-absorption processes. By integrating Eq.(1) along an optical path, the transmitted blackbody radiation intensity at one position y after self-absorption along the remaining pathway can be expressed as follows:

$$
I_{r}(y)=k(y) I_{b}(y) e^{-\int_{y}^{y \max } k\left(y^{\prime}\right) d y^{\prime}}
$$

Thus, the overall projected radiation intensity (as shown in iError! No se encuentra el origen de la referencia.(bottom)) at each pixel position is obtained as follows:

$$
I_{r}=\int_{y_{\min }}^{y_{\max }} I_{r}(y) d y
$$

The local extinction coefficient field $(k)$, as shown in iError! No se encuentra el origen de la referencia. (top), can be calculated through tomographic reconstruction from the overall optical thickness (KL) obtained from extinction images. Two numerical methods (onion-peeling method and inverse Radon transformation) for this reconstruction will be discussed in later analysis. The detailed methodology to obtain this KL value can be found in [6]. In addition, the soot volume fraction $\left(f_{v}\right)$ can be obtained from small particle Mie theory[11]:

$$
f_{v}=\frac{k \cdot \lambda}{k_{e}}
$$

where $k_{e}$ is dimensionless extinction coefficient which can be derived from Rayleigh-Debye-Gans (RDG) theory, as presented in [15][27].

Once the soot volume fraction has been derived from extinction images, the recorded radiation measured at each pixel can be deconvoluted to derive the local spectral emission rate $\left(I_{b} K\right)$ and temperature $(T)$ can be reconstructed, as shown in iError! No se encuentra el origen de la referencia. (bottom). 


\section{Experimental facility and optical setup}

All the measurements were carried out in a new high-pressure high-temperature test vessel capable of reproducing in-cylinder thermal dynamics conditions at top dead center (TDC) position of Diesel engines. This test rig is a constant pressure flow vessel where air pressure and temperature reach 15 $\mathrm{MPa}$ and $1100 \mathrm{~K}$, which is pretty similar to the one presented in [28][29]. Two optical accesses $181 \mathrm{~mm}$ in diameter are installed, which enable a large field of view on the spray. The detailed information about this kind of vessel can be found in [28].

A top view of the experimental arrangement is shown in iError! No se encuentra el origen de la referencia.. For extinction measurement, a high-output blue LED with a Peak wavelength $460 \mathrm{~nm}$ and $2 \mu$ s pulse duration was applied here as the light source. An engineered diffuser was placed next to the optical window to create a diffused Lambertian intensity profiles. On the other side of the chamber, a spherical lens ( $f=800 \mathrm{~mm}$ ) was used to reduce the effects of beam steering. After going through the beam splitter ( $50 \% / 50 \%)$, the transmitted LED light, as well as the flame luminosity, were collected by a high-speed CMOS camera (Photron SA-5, recording at 25khz) equipped with a bandpass filter (460 $\mathrm{nm}, 10 \mathrm{FWHM}$ ). The exposure time of the camera was set as $1.91 \mu \mathrm{s}$ with $704 \times 384$ pixels image resolution and the pixel/mm ratio is 6.48 .

Meanwhile, the soot radiation was directed into another two high-speed CMOS cameras (Photron SA5 , recording at $25 \mathrm{KHz}$ ) equipped with two bandpass filters (centered at $550 \mathrm{~nm}$ and $660 \mathrm{~nm}$, both with $10 \mathrm{~nm}$ FWHM) by means of two beam splitters (50\%/50\%). The exposure time of two cameras was set as $6.64 \mu$ s with $704 \times 384$ pixels image resolution and the pixel $/ \mathrm{mm}$ ratio is 6.54 . In order to transform grey levels into radiance values, calibration curves have been obtained by means of a tungsten-ribbon calibration lamp (Osram Wi17G), which was located at the same position of spray within the combustion chamber.

In order to check the extinction sensitivity with the spectral wavelength of illumination light, another red LED with a Peak wavelength $660 \mathrm{~nm}$ coupled with a corresponding filter (660 nm, 10 FWHM (full width at half maximum)) was also applied to do the DBI tests as a reference.

Additionally, $\mathrm{OH}^{*}$ chemiluminescence was also measured simultaneously (even though it is not shown in iError! No se encuentra el origen de la referencia.) to analyse the relative location between $\mathrm{OH}$ radical and soot cloud. An Andor Solis iStar intensified camera equipped with a $100 \mathrm{~mm}$ focal length $\mathrm{f} / 2$ UV objective and a $310 \mathrm{~nm}$ interference filter (FWHM = $10 \mathrm{~nm}$ ) was used. Only one image per injection event was recorded from $3 \mathrm{~ms}$ to $5 \mathrm{~ms}$ after start of energizing (ASOE) with a pixel $/ \mathrm{mm}$ ratio of 8.94. The flame lift-off length (LOL) was derived according to standard ECN processing method [30][31]. Besides, $\mathrm{OH}^{*}$ contour on the symmetric plane was also obtained through tomographic reconstruction. One example of the raw image and reconstructed one is shown in Fig.3.

Fig. 1 Reconstructed $O^{*}$ radiation distribution on the spray symmetric plane (top) and raw image (bottom). ( $P_{i n j}$ $=1500 \mathrm{bar}, \rho_{g}=22.8 \mathrm{~kg} / \mathrm{m} 3, T_{g}=1000 \mathrm{~K},\left[\mathrm{O}_{2}\right]=15 \%$ ).

\section{Test Matrix}

The standard Spray A injector with a single-hole nozzle $\left(d_{0}=89.4 \mu \mathrm{m}\right)$, as well as the standard fuel, $n$ dodecane, within ECN group have been investigated in this study. A long injection energizing time was set as $3.5 \mathrm{~ms}$ at every operating point, which results in an injection duration of $5 \mathrm{~ms}$, approximately, in order to achieve a quasi-steady state flame. The investigated operating conditions are summarized 
in Tab. 1. Starting from the reference condition (Operating point 2), parametric variations in injection pressure, ambient temperature and oxygen concentration were performed, while the ambient density was kept constant. For each operating condition, 40 injection cycles were recorded in order to reduce the cycle-to-cycle scattering.

Tab. 1 Test conditions.

\begin{tabular}{ccccc}
\hline Operating point & $\mathrm{P}_{\text {inj }}[\mathrm{bar}]$ & $\mathrm{T}_{\mathrm{g}}[\mathrm{K}]$ & $\rho_{\mathrm{g}}[\mathrm{kg} / \mathrm{m} 3]$ & $\mathrm{O}_{2}[\%]$ \\
\hline 1 & 1500 & 800 & 22.8 & 15 \\
2 & 1500 & 900 & 22.8 & 15 \\
3 & 1500 & 1000 & 22.8 & 15 \\
4 & 1000 & 900 & 22.8 & 15 \\
5 & 1500 & 900 & 22.8 & 21 \\
\hline
\end{tabular}

\section{Diagnostic methodology}

The present technique is based upon an assumption of axis-symmetry of the investigated flame. As a consequence, time- and sample-averaged radiation and extinction maps will be used. Therefore, the first issue to be addressed is the definition of the time window for averaging. iError! No se encuentra el origen de la referencia. shows a temporal and spatial flame luminosity map by integrating flame luminosity at each axial location for each frame of a natural luminosity with a $660 \mathrm{~nm}$ wavelength, namely IXT (Intensity-Axial-Time) plot [32] which was calculated as follows:

$$
I(x, t)=\int_{-y_{1}}^{y_{2}} I(x, y, t) d y
$$

where $x$ is the spray axial direction, $y$ is the spray radial direction, $y_{1}$ and $y_{2}$ are the flame boundary positions, all of them based upon radiation images. Even though this plot was obtained from averaged images of 40 repetitions, relatively high fluctuations can still be observed during this so-called quasisteady period. To skip these effects of turbulence-induced fluctuations, which may obviously pose questions on the assumption of spray symmetry, only the time-averaged images during this quasisteady period was focused in this study. The time-averaged interval starts from the time when the flame tip disappears from optical window until the end of injection, which is indicated by vertical dashed lines in iError! No se encuentra el origen de la referencia. for $P_{\text {inj }}=1500$ bar and $P_{\text {inj }}=1000$ bar. The period during which $\mathrm{OH}^{*}$ chemiluminescence is recorded is also indicated by red horizontal dashed lines. One example of this time- and sample-averaged raw soot radiation image and corresponding radial profiles are shown in iError! No se encuentra el origen de la referencia.. It can be observed that this averaged soot cloud is pretty axisymmetric. Consequently, the tomographic reconstruction can be carried out based on this kind of images. Furthermore, iError! No se encuentra el origen de la referencia. presents standard deviation (std) of soot radiation intensity divided by averaged intensity (avg). A strong scattering (more than 50\%) can be observed at the periphery of the flame, which can be naturally expected due to the turbulent fluctuation of the reaction front around that area. This zone should correspond to highest temperature and low soot volume fraction around stoichiometric conditions. In order to weaken this scattering, a threshold of $5 \%$ maximum radiation intensity was applied to leave out the highest std/avg zones.

Aside from radiation, input information for the method is local soot distribution. It is still a big challenge to get accurate quantitative soot extinction measurements as multiple parameters are not well known and are characterized by large uncertainties[15]. One source of the dominated uncertainties is the 
dimensionless extinction coefficient $k_{e}$ from RDG theory which depends on particle diameter, aggregate size and complex refractive index. According to the analysis in [15], the authors concluded that complex refractive index dominates the overall uncertainty.

The parameters (particle diameter, aggregate size and complex refractive index...) used to calculate $k_{e}$ through the RDG theory are referenced from standard ECN parameters[15]. It has to be pointed all these parameters are kept same for three wavelengths applied for both extinction and radiation measurements. As a consequence, the $k_{e}$ values are 7.59, 7.40 and 7.27 corresponding to blue (460 $\mathrm{nm})$, green $(550 \mathrm{~nm})$ and red $(660 \mathrm{~nm})$ wavelengths, respectively.

Besides onion-peeling method, the soot volume fraction is also reconstructed using an ECN recommended inverse Radon transformation as a reference. iError! No se encuentra el origen de la referencia. presents a comparison of SVF on the symmetric plane (top) and a radial distribution at $x=50$ $\mathrm{mm}$ (bottom) away from the nozzle orifice obtained from these two methods. Both methods show a good agreement on the magnitude all over the flame except the data on the symmetric axis, where onion-peeling method shows a higher noise level. However, considering Inverse radon method is not able to be applied for local temperature reconstruction, onion-peeling method is used for later analysis.

¡Error! No se encuentra el origen de la referencia. presents a comparison of axial KL extinction value from two tests at different wavelengths ( 460 and $660 \mathrm{~nm}$ ) under two ambient temperatures. To enable a comparison of $\mathrm{KL}$ at wavelength $460 \mathrm{~nm}$ to that at wavelength $660 \mathrm{~nm}$, the following relationship derived from Eq.(5) has been used:

$$
K L_{460}^{*}=K L_{660} \frac{\lambda_{660} \cdot k_{e 460}}{\lambda_{460} \cdot k_{e 660}}
$$

It can be seen both LED measurements follow the same trend, namely KL increases with higher ambient temperature and with both LEDs presenting a similar sensitivity with different operating conditions. It shows a pretty good agreement with [15] that the KL extinction signal from shorter wavelength light is stronger because of the higher sensitivity of shorter wavelength to nascent soot which has higher hydrogen-to-carbon $(\mathrm{H} / \mathrm{C})$ ratios, as explained in[15]. As a consequence, the parametric study in later section follows the suggestion from [15] that shorter wavelength $(460 \mathrm{~nm})$ is applied for the soot volume fraction analysis, as soot-generated extinction signal-to-noise ratio is higher.

As mentioned by [15], beam steering defined lower extinction detection limit. When the ambient temperature is at $800 \mathrm{~K}\left(\mathrm{P}_{\mathrm{inj}}=1500 \mathrm{bar}, \rho_{\mathrm{g}}=22.8 \mathrm{~kg} / \mathrm{m}^{3}, \mathrm{O}_{2}=15 \%\right)$, no soot was observed from radiation images. Thus, this condition was used here to check this lower extinction limit. iError! No se encuentra el origen de la referencia. presents soot volume fraction (mainly caused by beam steering) along spray axis under such condition derived from time-averaged KL map (liquid part was removed). The lower detection limit is seen to be smaller than $0.3 \mathrm{ppm}$ in general, and it is reduced to even less than 0.1 $\mathrm{mm}$ after $45 \mathrm{~mm}$. Thus, the extinction caused by beam steering is negligible compared with a magnitude $10 \mathrm{ppm}$ caused by soot extinction as shown in later section.

To close this section, an analysis of the sensitivity of temperature results to the selection of the wavelength for the extinction and radiation measurements is presented. Fig. 11 presents a comparison of axial (left) and radial (right) soot temperature obtained using a KL map derived from a red (660 nm) or blue $(460 \mathrm{~nm})$ wavelength, combined with a radiation measured at $660 \mathrm{~nm}$. The axial temperature distribution presented here and in later analysis is averaged from both half flame part at $1 \mathrm{~mm}$ away from symmetry axis, in order to skip the noise along symmetry axis brought about by deconvolution. As we know from iError! No se encuentra el origen de la referencia., the different wavelengths of extinction light result in an apparent difference on KL value. However, it can be seen from Fig. 11 this $\mathrm{KL}$ difference does not bring significant uncertainties on soot temperature, especially at the high 
sooting region at spray center where the difference from these two wavelengths is below $20 \mathrm{~K}(1 \%)$. The big differences appear at the soot initial location, where the soot amount uncertainty caused by wavelength selection is bigger because of the different properties of nascent soot, as mentioned above. The low signal-to-noise ratio $(\mathrm{S} / \mathrm{N})$ could be another factor for these differences, as shown in Fig. 12 , where the noise information is KL value mainly caused by beam steering (derived from the case presented in iError! No se encuentra el origen de la referencia.) and signal is KL value of soot extinction from target case. It can be seen that the low $\mathrm{S} / \mathrm{N}$ area locates at soot initial location and flame periphery.

Fig. 13 presents a comparison of axial (left) and radial (right) soot temperature obtained from $550 \mathrm{~nm}$ radiation wavelength and $660 \mathrm{~nm}$ radiation wavelength respectively, while the extinction wavelength used here is $460 \mathrm{~nm}$. The trends are pretty similar with Fig. 11, in the sense that bigger uncertainties are located at the upstream and periphery of the flame where the temperature difference between two wavelengths is higher than $40 \mathrm{~K}(2 \%)$. Note that the highest experimental scattering has been observed at the largest radial location ( $i$ Error! No se encuentra el origen de la referencia.), which may also play a role in the observed uncertainty related to wavelength around that area.

It is known that soot radiation intensity increases with higher wavelength, as a consequence, $660 \mathrm{~nm}$ was finally selected for later analysis in order to reduce the uncertainty induced by noise.

\section{Theoretical analysis and uncertainty quantification}

To evaluate the algorithm performance by removing the effects of experimental uncertainties on soot temperature analysis, a theoretical approach was conducted. The same wavelength for extinction and radiation was used, and by means of which the main uncertainty factor caused by the selection of the soot refractive index was removed. At a given distance away from injector tip, two local extinction coefficient (k) radial profiles (with peak $\mathrm{fv}=40 \mathrm{ppm}$ and $80 \mathrm{ppm}$ respectively, as shown in Fig. 14(a)) and one temperature radial profile (Fig. 14(b)) are assumed based on dividing the flame profile in finite elements. Projected radiation intensity profiles accumulated based on assumed $k$ and $T$ are presented in Fig. 14 (a) as black curves, which should represent the radiation recorded by the camera. Based on these theoretical radiation intensity and soot profiles, temperature is reconstructed and compared with the original one. The errors between the assumed temperature and reconstructed ones are presented in Fig. 14 (b) as red lines, being negligible for both calculations with different soot levels. This shows that the algorithm should be theoretically able to derive the temperature from soot and radiation information. Furthermore, this result is valid for the chosen temperature and both assumed soot profiles, which are derived from the most sooting conditions in this study $\left(\mathrm{T}_{\mathrm{g}}=1000 \mathrm{~K}\right.$ case).

Based upon Fig. 14 information, the local blackbody intensity $\left(I_{b}\right)$ will increase with radial distance because it is mainly governed by local temperature. Besides, soot volume fraction reduces with increasing radial distance, which leads a lower self-absorption and therefore will favour a higher transmitted intensity. At the same time, the smaller $k$ will directly result in a smaller local spectral emission rate $\left(\mathrm{I}_{\mathrm{b}} \mathrm{K}\right)$ as well as projected intensity. As a balance, the overall projected radiation intensity increases with radial distance until around $4 \mathrm{~mm}$ from the spray symmetry axis, and then decreases until the edge of the flame $(5 \mathrm{~mm})$. Furthermore, due to the above described balance between emission and absorption related to the soot population, the projected intensity does not present a strong sensitivity with soot $\mathrm{k}$ as shown in Fig. 14 (a), where the overall projected intensity increases only $16 \%$ in average within $4 \mathrm{~mm}$ as a result of increasing soot volume fraction by $100 \%$. 
Based upon the previous theoretical analysis, an evaluation of uncertainties on reconstructed soot volume fraction and temperature caused by scattering of digital value has been carried out. For that purpose, the recorded radiation signals as recorded by the camera in digital levels, have been artificially perturbed with random noise to evaluate the corresponding effect on the measured quantities. As for soot volume fraction, a constant digital value is assumed for background illumination intensity (3000 counts) and a matrix of Gaussian noise with a zero mean and a standard deviation of 20 counts is added on transmitted intensity as derived from the radial profiles shown above. The wavelength induced uncertainties on soot volume fraction have been discussed in detail in [15][33], which are mainly contributed by the uncertainty in soot refractive index, thus it will not be discussed here. The extinction wavelength used here is $460 \mathrm{~nm}$. As for soot temperature, the same Gaussian noise is added on flame radiation intensity while no noise is assumed on soot volume fraction profiles.

Fig. 15 displays the correlation between the original numerical input and reconstructed data from CER methodology, where the input soot volume fraction follows the radial profile in Fig. 14(a) with $\mathrm{fv}_{\max }=$ $40 \mathrm{ppm}$ and input temperature follows the temperature radial profile in Fig. 14 (b). Even though it is not shown here, the evolution of case with $\mathrm{fv}_{\max }=80 \mathrm{ppm}$ has also been carried out and the results are pretty similar. Fig. 15 shows that the reconstructed soot volume fraction and temperature presents higher levels of scattering in for the highest $\mathrm{fv}$ and lowest temperature values. In other words, the digital induced uncertainty from CER methodology increases when it is approaching spray symmetry axis. This is due to the fact that the reconstruction starts from discrete out layers of the spray and towards to the spray symmetry axis. As a consequence, the reconstructed values from each layer will be affected by the accumulated uncertainty from all layers out of it. The averaged absolute errors over the whole fields are $1 \mathrm{ppm}$ and $17 \mathrm{~K}$ corresponding soot volume fraction and soot temperature respectively. This uncertainty analysis on digital noise indicates that the CER methodology is robust.

\section{Results and discussion}

This section addresses the analysis of the experimental information for the different operating conditions. As a reference for the analysis below, results for four different operating conditions are included in Fig. 16. Starting from the nominal one (a), an increase in ambient gas temperature (b), decrease in injection pressure (c) and increase in oxygen concentration in the ambient gas (d) are reported. Soot volume fraction (fv) and Temperature ( $T$ ) distribution on the flame symmetric plane reconstructed from blue $(460 \mathrm{~nm})$ LED KL map and red $(660 \mathrm{~nm})$ radiation images are provided. Meanwhile, $\mathrm{OH}^{*}$ contours derived from deconvolution of $\mathrm{OH}^{*}$ images, as well as $\mathrm{LOL}$, are also presented here to check the relative location between soot cloud and $\mathrm{OH}$ radical. It must be mentioned that $\mathrm{OH}^{*}$ chemiluminescence visualization window is $5 \mathrm{~mm}$ shorter than the one for soot tests. A crosssectional average equivalence ratio at $\operatorname{LOL}\left(\bar{\phi}_{H}\right)$ is also presented in Fig. 16. Pickett and Siebers have proven $\bar{\phi}_{H}$ is a good indicator for soot formation[11].

It is well known that net soot production is the balance between soot formation and soot oxidation. Soot formation rate is higher than oxidation rate from the initial soot location to the fv peak location, while oxidation rate is more dominated from fv peak location to flame tip. As a result, Fig. 16 shows that the high soot concentration region locates at the centre of flame for all cases, where the local temperature is lower than around $2200 \mathrm{~K}$ and no $\mathrm{OH}$ radical is observed. When shifting downstream 
from the maximum location, soot amount decreases dramatically because of the lower formation rate and faster oxidation rate caused by fuel-lean mixture and appearance of $\mathrm{OH}$ respectively. This trend is consistent with previous research [15][16][17]. On the other hand, the high temperature soot location shows a consistency with $\mathrm{OH}^{*}$ area. The temperature gradient is quite big at upstream locations, where the temperature increases from spray axis to the flame periphery, while the temperature distribution becomes more uniform when moving downstream. It is consistent with Aizawa et al's research [34], where they measured the in-flame temperature at different location by means of a thermocouple.

In the following subsections, the detailed spatial distribution of temperature and soot when changing one operating condition will be analysed. For that purpose, a so-called flame coordinate $\left(1 / \phi_{c l}(x)\right)$ is applied in later parametric discussion to normalize the evolution in terms of iso-equivalence ratio. $\phi_{c l}(x)$ is the mixture-fraction based equivalence ratio on the spray axis at any axial location( $\left.\mathrm{x}\right)$, which was estimated using following relationship:

$$
\phi_{c l}(x)=\frac{Z_{c l}(x)}{1-Z_{c l}(x)} \cdot \frac{1-Z_{s t}}{Z_{s t}}
$$

where $Z_{c l}(x)$ is the fuel mixture fraction along spray axis which is obtained from 1D spray model, which provides reasonable distribution of mixing processes within the reacting flame according to recent results [35]. $Z_{s t}$ is the stoichiometric mixture fraction. Idicheria and Pickett [36] used a similar definition, but they base their flame coordinate on a cross-sectional average equivalence ration. The advantage of the present definition is that it reaches a value of unity on the flame tip, i.e. at the tip of the diffusion flame, which is more intuitive than the previous one.

\subsection{Ambient temperature}

Soot volume fraction ( $\mathrm{fv}$ ) and soot temperature $(\mathrm{T})$ distribution with ambient temperature variation can be seen from Fig. 16(a) and Fig. 16(b). Soot volume fraction and soot temperature along spray axis at both temperatures are shown in Fig. 17, both on physical and flame coordinates. As expected, an increase in ambient temperature results in a shorter LOL, a higher $\bar{\phi}_{\mathrm{H}}$, higher soot temperature and higher soot production. As shown in Fig. 17, the peak soot volume fraction location is shifted upstream around $5 \mathrm{~mm}$ when increasing ambient temperature. When using the flame coordinate, the peak value in both cases is reached at around $1 / \phi_{c l} \sim 0.5$. It can be seen from Fig. 17(b) that the soot volume fraction at $1000 \mathrm{~K}$ ambient temperature is around three times larger than that of $900 \mathrm{~K}$ from the start of soot to the peak. Downstream from the peak, the difference becomes smaller and eventually converges close to the window limit. In agreement with the 1D spray model, the stoichiometric surface at spray axis locates at around $100 \mathrm{~mm}$.

On the other hand, the axial soot temperature difference between two cases is pretty uniform along the whole flame coordinate. The increase of axial soot temperature when moving downstream indicates the progress of fuel-air mixing. The average temperature difference is just $48 \mathrm{~K}$ (from 0.4 to 0.6 flame coordinate), which is related to the difference in adiabatic flame temperature. The large variation in soot volume fraction compared to temperature hints at the possibility that the higher flame temperature at $1000 \mathrm{~K}$ ambient temperature is not the governing factor for the observed much higher soot production. A more plausible effect can be the richer flame conditions found at the shorter 
lift-off length (larger $\bar{\phi}_{\mathrm{H}}$ ), which would produce to more soot precursors and result in a faster soot rise from the very same flame base.

$\phi$-T plots and relative soot distribution at two ambient temperature cases are shown in Fig. 18, where temperature and soot volume fraction are derived from Fig. 16, while $\phi$ is obtained from 1D spray model. Such plots presented here show soot production resulting from the competition between formation and oxidation processes, which are different from traditionally derived $\phi$ - $T$ plots presented in [37][38], where only the soot formation factor is studied. As shown in Fig. 18, soot distribution starts at around rich low temperature locations, which occur downstream of lift-off length, grows towards decreasing equivalence ratio and increasing temperatures, reaching a maximum value at a local equivalence ratio of around 2-2.5, in agreement with the previous on-axis results in terms of flame coordinate. Further downstream, soot volume fraction decreases when moving towards lower equivalence ratio and higher temperatures up to stoichometric locations, from which temperatures tend to drop strongly. Soot volume fraction values at both temperature values decrease dramatically when $\phi$ value is smaller than 1 , where the spray is out of stoichiometric surface, because of soot oxidation.

From the superposition of both maps in Fig. 18(c), the $\phi$-T plot of $1000 \mathrm{~K}$ case is seen to be shifted towards higher temperatures, compared with that of $900 \mathrm{~K}$ case, consistent with the higher local temperature expected at every equivalence ratio value. Furthermore, it can also be found from Fig. 18(c) that initial soot cloud is found at richer equivalence ratio for the higher ambient temperature case, consistently with the shorter lift-off length. This confirms that the higher soot production in the spray central locations observed in Fig. 16 is linked to the soot formation history, i.e. more soot precursors are formed because of shorter LOL, which seem to govern the increase in soot within the flame more than the modest increase in temperature. In addition, the corresponding adiabatic temperatures at stoichiometric conditions are presented in Fig. 18(c) as vertical dashed lines. Nearly all points are below the corresponding adiabatic temperatures, with the closest points occurring around stoichiometric locations, which indicates that the experimental results are consistent. Values above this limiting point, which may be linked to the uncertainties in the measurement methodology, are most often found at lean equivalence ratio locations, where soot volume fraction is pretty low.

\subsection{Injection pressure}

Soot volume fraction and soot temperature with injection pressure variation are shown in Fig. 16(a) and Fig. 16(c), with corresponding on-axis values plotted in Fig. 19. Air entrainment rate at any axial location is the same for both cases because spray spreading angle and Tad do not change with injection pressure. Thus, flame coordinate transformation is essentially the same between both injection pressure values.

As expected, lower injection pressure leads to a higher soot production, with a similar location of $\mathrm{fv}$ peak, as shown in Fig. 19. The axial soot temperature is slightly higher with higher injection pressure. However, the average temperature difference is just $35 \mathrm{~K}$ (from 0.4 to 0.6 flame coordinate), which is almost negligible compared with uncertainty values because of similar mixture fraction distribution. Thus, local temperature values are not probably the governing factor on soot production. As presented in Fig. 16 (a) and Fig. 16 (c), $\bar{\phi}_{\mathrm{H}}$ increases slightly with lower injection pressure because of the shorter LOL, which may also contribute on soot formation. A third factor on this higher soot production for lower injection pressure is the longer residence time for soot production caused by the lower velocity.

These findings can also be observed by the $\phi$-T plot, as shown in Fig. 20. The soot distribution of both cases in such coordinates is pretty similar. High soot locations are also pretty similar ( $\mathrm{T} \approx 2050 \mathrm{~K}$, $\phi \approx 2$ ), with the only difference being related to the soot volume fraction peak values. Once again, temperature distribution is below stoichiometric adiabatic flame temperature. Such results seem to 
indicate that injection pressure does not produce significative differences neither on equivalence ratio nor flame temperature, and confirms that the higher net soot production at 1000 bar injection pressure case should be mainly due to the longer residence time.

\subsection{Oxygen concentration}

Soot volume fraction and soot temperature along spray axis and flame coordinate with oxygen concentration variation are presented in Fig. 21(a) and Fig. 21(b) respectively. It can be found that the peak fv location moves farther away from injector nozzle with lower oxygen concentration, in agreement with the oxygen dilution effect. However, soot distribution becomes quite similar when plotted in terms for flame coordinate, which normalize the oxygen entrainment effect. Some differences are visible on the rising part of soot volume fraction, and peak values occur at richer equivalence ratio for the higher oxygen concentration, while there is a full overlap in values below the peak soot production. Compared to ambient temperature and injection pressure variations, the effects of oxygen on soot temperature is much greater, with an axial average temperature difference of $168 \mathrm{~K}$ (from 0.4 to 0.6 flame coordinate). Considering the modest effect on soot distribution, this is another indication that flame temperature is not the governing factor on soot formation for the operating conditions studied in this paper. When plotted in flame coordinates, soot production within the flame seems to be more linked to differences in equivalence ratio at the lift-off length, with the consequent effects on soot precursors at the flame base. The similar distribution observed in flame coordinate indicates that the large observed difference in spatial locations with oxygen content seem to be linked to entrainment effect.

Fig. 22 (a) presents soot volume fraction and soot temperature along spray radial direction at same flame coordinate $(0.42$, which corresponds to $49.5 \mathrm{~mm}$ and $40 \mathrm{~mm}$ from the axis for $15 \%$ and $21 \%$ oxygen content, respectively). It can be seen that soot cloud radius is narrower and fv gradient is greater at $21 \%$ oxygen concentration than that at $15 \%$ oxygen concentration. In addition, the soot temperature difference increases with flame radius. They are caused by the sharper equivalence ratio gradient under higher oxygen concentration. The axial optical thickness (KL) along flame coordinate is shown in Fig. 22(b). KL is an integrated parameter and it is proportional to the integrated total soot mass along the line-of-sight optical path. It is interesting to note that the trend of KL with oxygen is opposite to the fv one, which increases with lower oxygen concentration. That can be explained from Fig. 22(a), where the optical path at $15 \%$ oxygen concentration is longer and the fv value is higher than at $21 \%$ after around $2 \mathrm{~mm}$. As a result, the overall soot production of the $15 \%$ case is higher than that of the $21 \%$ case.

The $\phi$-T plots derived from Fig. 16(a) and Fig. 16(d) are shown in Fig. 23. The main observation is that the $\phi$-T plot is shifted towards higher temperature values, because of fact that flame temperature of $21 \%$ oxygen case is higher all over the spray. In both cases, the maximum soot temperature is located mainly below the stoichiometric adiabatic flame temperature.

\section{Conclusions}

In this study, a combined extinction and radiation (CER) methodology has been developed to investigate the soot temperature and soot production of quasi-steady Diesel sprays at various operating conditions from Engine Combustion Network. All experiments were performed in a constant pressure flow vessel equipped with a single-hole injector. A 1D spray model was also applied to substantiate the analysis. The main conclusions of this study are summarized below: 
- The CER methodology has been successfully applied on Diesel in-flame soot temperature quantification by considering self-absorption issues. The diagnostics sensitivity for both extinction and radiation measurements was checked at two different wavelengths. The soot temperature uncertainty caused by extinction is much less than that of soot amount. The uncertainty is much higher at upstream locations close to the lift-off length and at the periphery of flame, which is mainly caused by the smaller signal-to-noise ratio at these regions.

- Higher ambient temperature results in a much higher soot production, with less effect on measured soot temperature. On the other hand, the $\bar{\phi}_{H}$ increases noticeably because of much shorter lift-off length.

- A lower injection pressure leads to a higher soot production. But the measured soot temperature with different injection pressure is pretty similar because of similar fuel-air mixture distribution.

- A higher ambient oxygen concentration brings a very important increase on soot temperature, with a modest effect on soot production.

- Considering the sensitivity observed for all three parametric variation, peak soot production within the flame seems to be governed mainly by equivalence ratio at the lift-off length rather than by local temperature. Additionally, residence time plays a role for injection pressure variations.

\section{Acknowledgements}

This study was partially funded by the Ministerio de Economía y Competitividad from Spain in the frame of the CHEST Project (TRA2017-89139-C2-1-R) and China Postdoctoral Science Foundation (2018M642176). This study was also partially supported by State Key Laboratory of Engines, Tianjin University

\section{References}

[1] S.A. Skeen, J. Manin, L.M. Pickett, E. Cenker, et al., A progress review on soot experiments and modeling in the Engine Combustion Network (ECN), SAE Int. J. Engines 9 (2016) 883898.

[2] H. Zhao, N. Ladommatos, Optical Diagnostics for soot and temperature measurement in diesel engines, Prog. Energy Combust. 24 (1998) 221-255.

[3] M.P.B. Musculus, S. Singh, R. D. Reitz, Gradient effects on two-color soot optical pyrometry in a heavy-duty DI diesel engine. Combust. Flame 153 (2008) 216-227.

[4] J.Zhang, W.Jing, W.L.Roberts, T. Fang, Soot temperature and KL factor for biodiesel and diesel spray combustion in a constant volume combustion chamber. Appl. Energy 107 (2013) 52-65.

[5] F. Payri, J. Pastor, J. García, J. Pastor, Contribution on the application of two-colour imaging to diesel combustion. Meas.Sci.Technol., 18 (2007) 2579-2598.

[6] J. Pastor, J. M. Garcia-Oliver, A. García et al., Soot Quantification of Single-Hole Diesel Sprays by Means of Extinction Imaging, SAE Int. J. Engines 8 (2015) 2068-2077.

[7] C. Micó, Development of measurement and visualization techniques for characterization of mixing and combustion processes with surrogate fuel. Doctoral Thesis, Universitat Politecnica de Valencia, 2015.

[8] R. Viskup, T. Stanger, L. del Re, T. Reinisch, A. Bergmann, Development of In-Situ, Full Stream, Laser Induced Incandescence Technique for Measurement of Transient Soot Emissions. SAE Tech.Pap. 2013-24-0169 (2013).

[9] H. Liu, S. Ma, Z. Zhang, M. Yao, Study of the control strategies on soot reduction under earlyinjection conditions on a diesel engine, Fuel 139 (2015) 472-481. 
[10]S. Johan, High Repetition Rate Laser Diagnostics for Combustion Applications, Lund University, 2012

[11]L.M. Pickett, D.L. Siebers, Soot in diesel fuel jets: effects of ambient temperature, ambient density, and injection pressure. Combust. Flame 138 (2004) 114-135.

[12]M.P.B. Musculus, L. M. Pickett, Diagnostic considerations for optical laser-extinction measurements of soot in high-pressure transient combustion environments. Combust. Flame 141 (2005) 371-391

[13]L.Zheng, X. Ma, Z.Wang, J. Wang, An optical study on liquid-phase penetration, flame lift-off location and soot volume fraction distribution of gasoline-diesel blends in a constant volume vessel, Fuel 139 (2015) 365-373.

[14]J. V. Pastor, J.M. García-Oliver, A. García, C.M. Reche, et al., Application of optical diagnostics to the quantification of soot in $\mathrm{n}$-alkane flames under diesel conditions, Combust. Flame 164 (2016) 212-223.

[15]J. Manin, L. Pickett, S.A. Skeen, Two-Color Diffused Back-Illumination Imaging as a Diagnostic for Time-Resolved Soot Measurements in Reacting Sprays. SAE Int. J. Engines 6 (2013) 19081921.

[16]S.A. Skeen, J.Manin, K. Dalen, L.M.Pickett Extinction-based imaging of soot processes over a range of diesel operating conditions. 8th U.S. National Combustion Meeting, Canyons resort in Park, USA, 19 May -22 May, 2013.

[17]M.Bardi, G. Bruneaux, A.Nicolle, O.Colin, Experimental Methodology for the Understanding of Soot-Fuel Relationship in Diesel Combustion: Fuel Characterization and Surrogate Validation, SAE Tech.Pap. 2017-01-0721 (2017).

[18]F.R. Westlye, K. Penney, A. Ivarsson, L.M. Pickett, J.Manin, S.A. Skeen, Diffuse backillumination setup for high temporally resolved extinction imaging, Applied Optics 56 (2017) 5028-5038.

[19]Engine Combustion Network webpage: http://www.sandia.gov/ecn (online).

[20] S.Skeen, J.Manin, L.Pickett, K. Dalen, A. Ivarsson, Quantitative Spatially Resolved Measurements of Total Radiation in High-Pressure Spray Flames, SAE Technical Paper 201401-1252 (2014).

[21]M. Bolla, M. A.Chishty, E. R. Hawkes, Q.N. Chan, et al., Influence of turbulent fluctuations on radiation heat transfer, NO and soot formation under ECN Spray A conditions, Proc. Combust. Inst. 36 (2017) 3551-3558

[22]J.V. Pastor, J.J. López, J.M.García, J.M. Pastor, A 1D model for the description of mixingcontrolled inert diesel sprays, Fuel 87 (2008) 2871-85.

[23]J.M.Desantes, J.V. Pastor, J.M.García, J.M. Pastor. A 1D model for the description of mixingcontrolled reacting diesel sprays. Combust. Flame 156 (2009) 234-249.

[24]J.M.Desantes, J.M.García, T. Xuan, W. Vera-Tudela, A study on tip penetration velocity and radial expansion of reacting diesel sprays with different fuels. Fuel 207 (2017) 323-335.

[25]Guillaume Legros et al, Simultaneous soot temperature and volume fraction measurements in axis-symmetric flames by a two-dimensional modulated absorption/emission technique, Combust. Flame, 162 (2015) $2705-2719$.

[26]M.F. Modest, Radiative Heat Transfer (second ed.), Academic Press, USA, 2003.

[27]U. O. Koylu, G. M. Faeth, Optical properties of overfire soot in buoyant turbulent diffusion flames at long residence times. J. Heat Transfer. 116 (1994) 152-159.

[28]R. Payri, J.M. García-Oliver, M. Bardi, J. Manin, Fuel temperature influence on diesel sprays in inert and reacting conditions, Appl. Therm. Eng. 35 (2012) 185-195.

[29]R. Payri, J.M. García-Oliver, T. Xuan, M. Bardi, A study on diesel spray tip penetration and radial expansion under reacting conditions. Appl.Therm.Eng. 90 (2015) 619-629.

[30]D.L. Siebers, B. Higgins, Flame Lift-Off on direct-injection Diesel sprays under quiescent conditions, SAE Tech.Pap. 2001-01-0530 (2001). 
[31]J. Benajes, R. Payri, M. Bardi, P. Martí-Aldaraví, Experimental characterization of Diesel ignition and lift-off length using a single-hole ECN injector. Appl. Therm. Eng. 58 (2015) 554563.

[32]A.Moiz, M. Ameen, L.Seong-Young, S. Som, Study of soot production for double injections of n-dodecane in $\mathrm{Cl}$ engine-like conditions. Combust. Flame 173 (2016) 123-131.

[33]S. Skeen, K. Yasutomi, E. Cenker, B. Adamson, et al., Observations of Soot Optical Property Characteristics Using High-Speed, Multiple Wavelength, Extinction Imaging in Heavy-Duty Diesel Sprays, SAE Tech.Pap. 2018-01-0233 (2018).

[34]T.Aizawa, T.Harada, K.Kondo, T.Adachi, B.Zhou J. Kusaka, Thermocouple temperature measurements in diesel spray flame for validation of in-flame soot formation dynamics, Int. J. Engine Res. 18 (2016) $453-466$

[35]J.M.García-Oliver, L.M. Malbec, H. B.,Toda, G.Bruneaux, A study on the interaction between local flow and flame structure for mixing-controlled diesel sprays, Combust. Flame, 179 (2017) 157-171.

[36]C.Idicheria, L.Pickett, Soot Formation in Diesel Combustion under High-EGR Conditions, SAE Technical Paper 2005-01-3834 (2005).

[37]T. Kamimoto, M. Bae, High Combustion Temperature for the Reduction of Particulate in Diesel Engines. SAE Tech.Pap. 880423 (1988).

[38]L.Pickett, J.Caton, M. Musculus, A.Lutz, Evaluation of the equivalence ratio-temperature region of diesel soot precursor formation using a two-stage Lagrangian model, Int. J. Engine Res. 7 (2006) 349-370. 

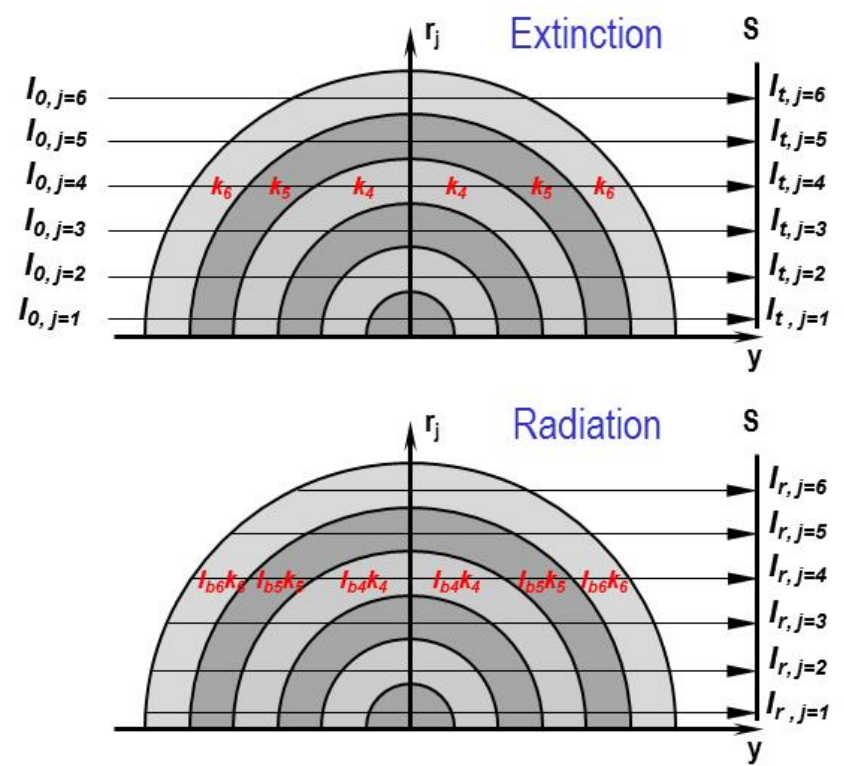

Fig. 2 Schematic of extinction and radiation optical path of a half soot cloud cross section at a given distance away from injector tip. Io represents the background illumination intensity, $k$ represents local spectral absorption coefficient, It is the transmitted background intensity, $I_{b}$ is the blackbody radiation intensity, $I_{r}$ is the projected radiation intensity, $S$ represents projected line provided by same pixel with soot cloud radius( $N$ ) from spray axis to soot boundary, ( $N$ is exampled as 6 here). Modified from Fig.2 in [25].

\section{Extinction}

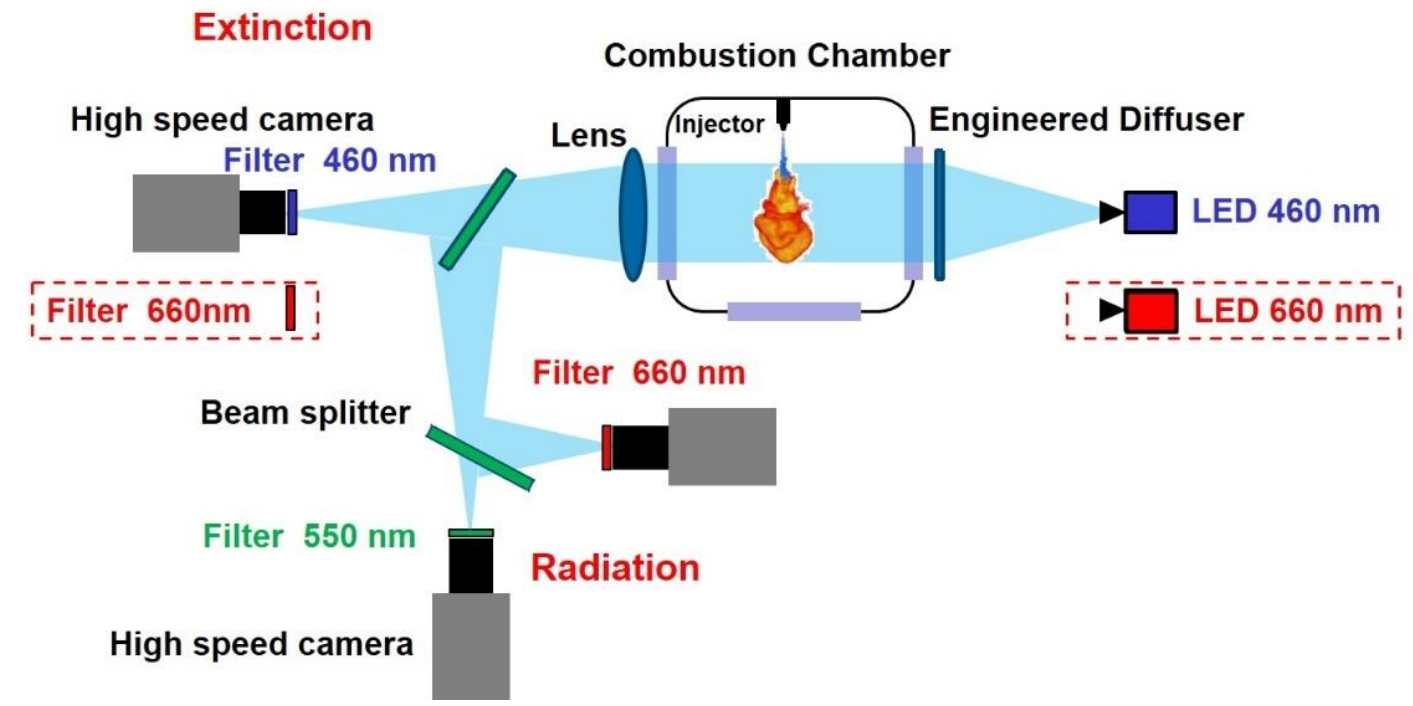

Fig. 3 Experimental layout for soot tests (top view) 

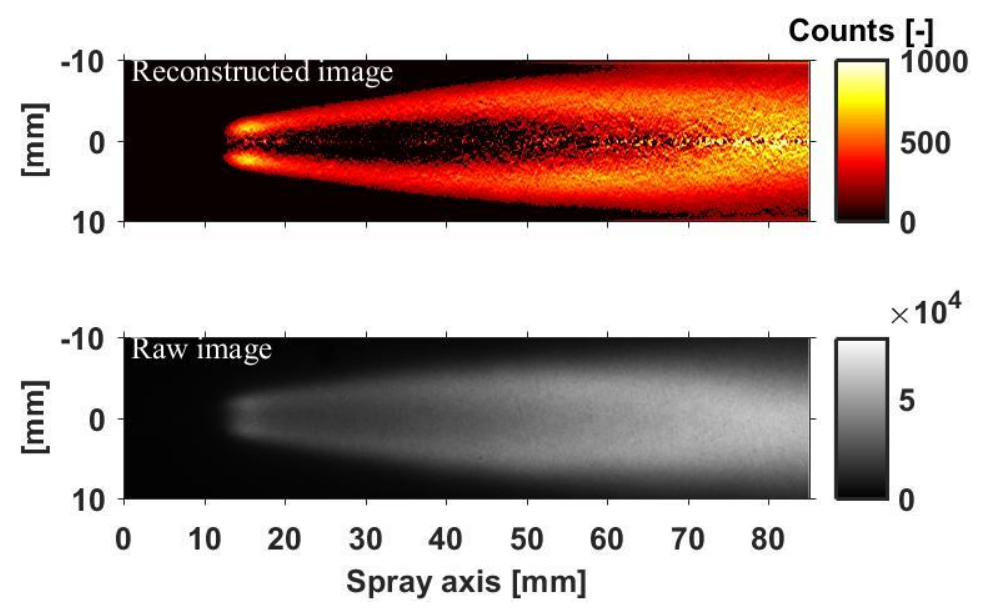

Fig. 4 Reconstructed $\mathrm{OH}^{*}$ radiation distribution on the spray symmetric plane (top) and raw image (bottom). ( $P_{i n j}$ $\left.=1500 \mathrm{bar}, \rho_{g}=22.8 \mathrm{~kg} / \mathrm{m} 3, \mathrm{~T}_{g}=1000 \mathrm{~K},\left[\mathrm{O}_{2}\right]=15 \%\right)$.

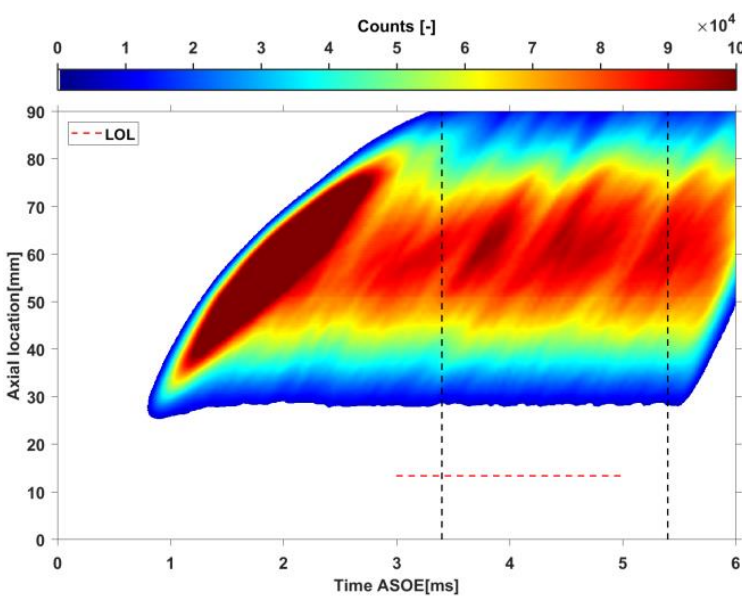

(a) $P_{\text {inj }}=1500$ bar, $\rho_{g}=22.8 \mathrm{~kg} / \mathrm{m3}, T_{g}=1000 \mathrm{~K},\left[\mathrm{O}_{2}\right]=15 \%$.

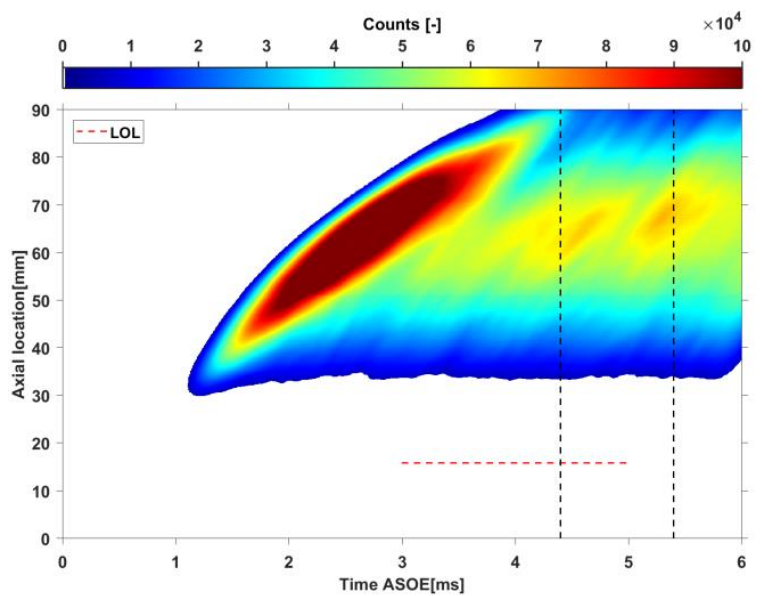

(b) $P_{\text {inj }}=1000 \mathrm{bar}, \rho_{g}=22.8 \mathrm{~kg} / \mathrm{m3}, T_{g}=900 \mathrm{~K},\left[\mathrm{O}_{2}\right]=15 \%$. resent the time-averaged zone for steady soot analysis.
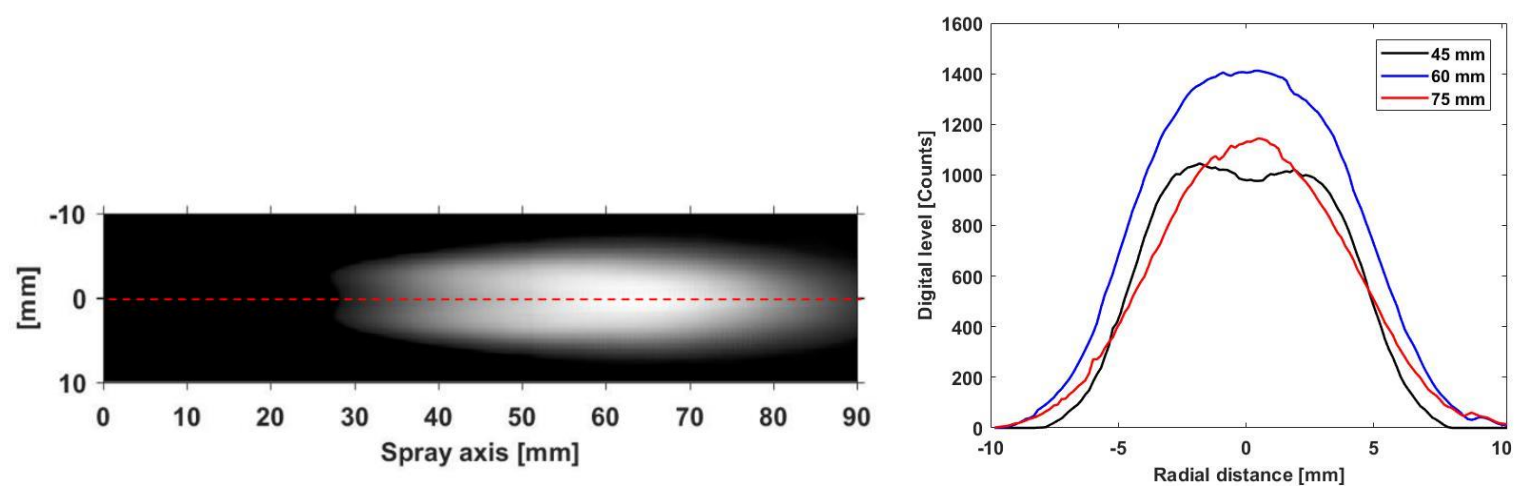

Fig. 6 Example of time- and sample-averaged raw soot radiation image(left) and corresponding radial profile at $45 \mathrm{~mm}, 60 \mathrm{~mm}$ and $75 \mathrm{~mm}$ away from injector tip (right). ( $P_{i n j}=1500 \mathrm{bar}, \rho_{g}=22.8 \mathrm{~kg} / \mathrm{m}^{3}, T_{g}=1000 \mathrm{~K}$, $\left.\left[\mathrm{O}_{2}\right]=15 \%\right)$. 


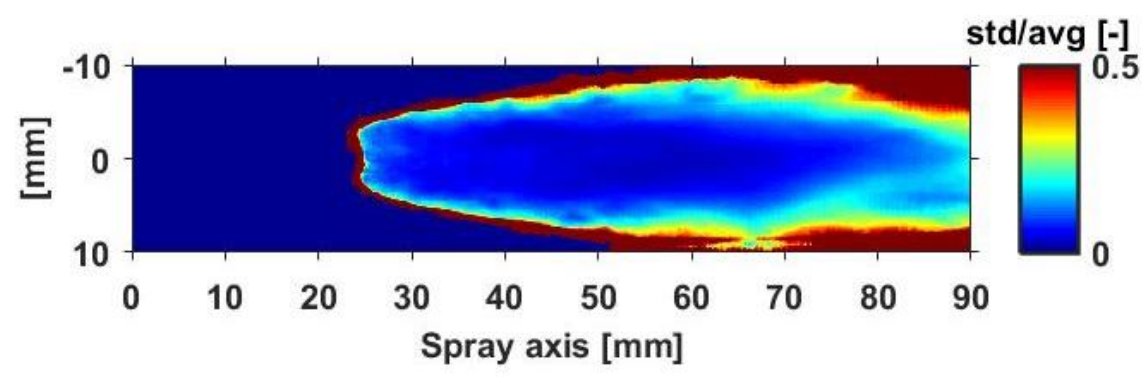

Fig. 7 Standard deviation(std) of soot radiation intensity divided by averaged intensity during flame quasisteady period. ( $P_{i n j}=1500 \mathrm{bar}, \rho_{g}=22.8 \mathrm{~kg} / \mathrm{m}^{3}, T_{g}=1000 \mathrm{~K},\left[\mathrm{O}_{2}\right]=15 \%$ ).
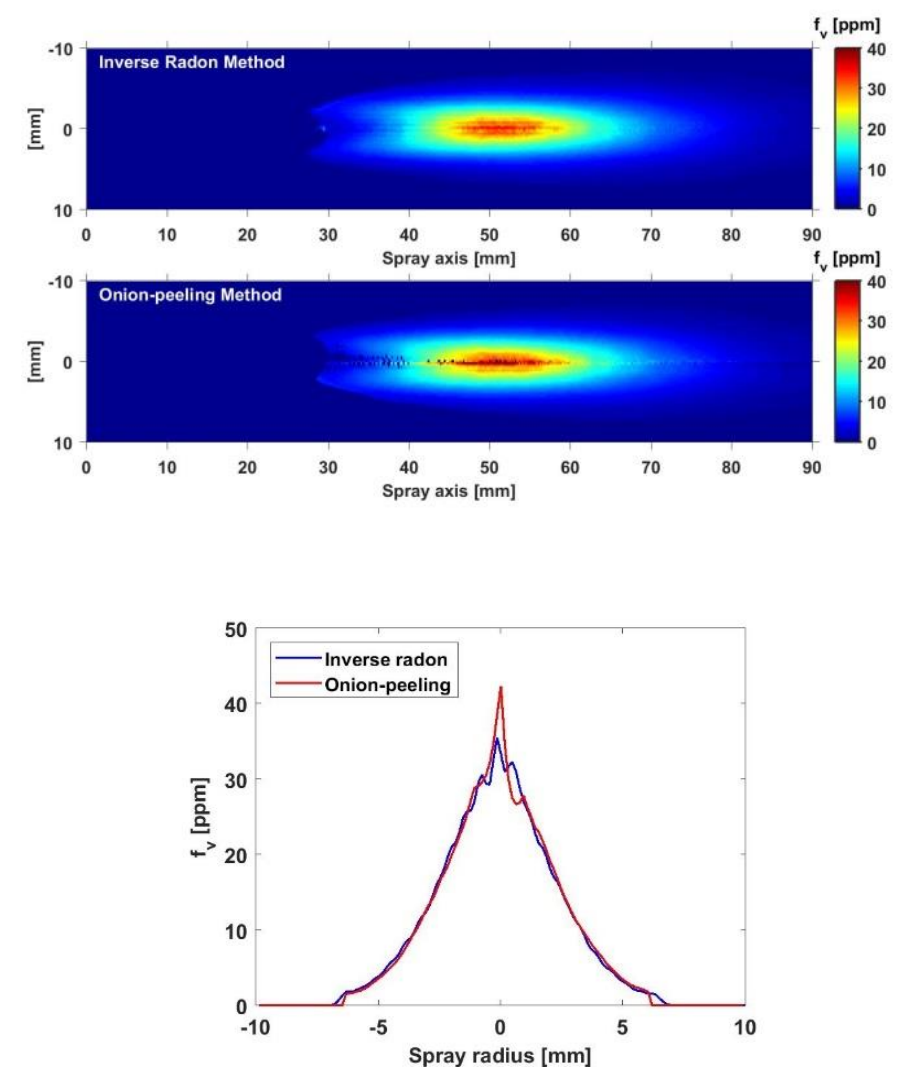

Fig. 8 Soot volume fraction on symmetric plane (top) and a radial distribution at $x=50 \mathrm{~mm}$ (bottom) of the flame after reconstruction from Blue $(460 \mathrm{~nm})$ LED KL maps with inverse radon method and onion-peeling method respectively $\left(P_{i n j}\right.$ $\left.=1500 \mathrm{bar}, T_{g}=1000 \mathrm{~K}, \rho_{g}=22.8 \mathrm{~kg} / \mathrm{m}^{3},\left[\mathrm{O}_{2}\right]=15 \%\right)$. 


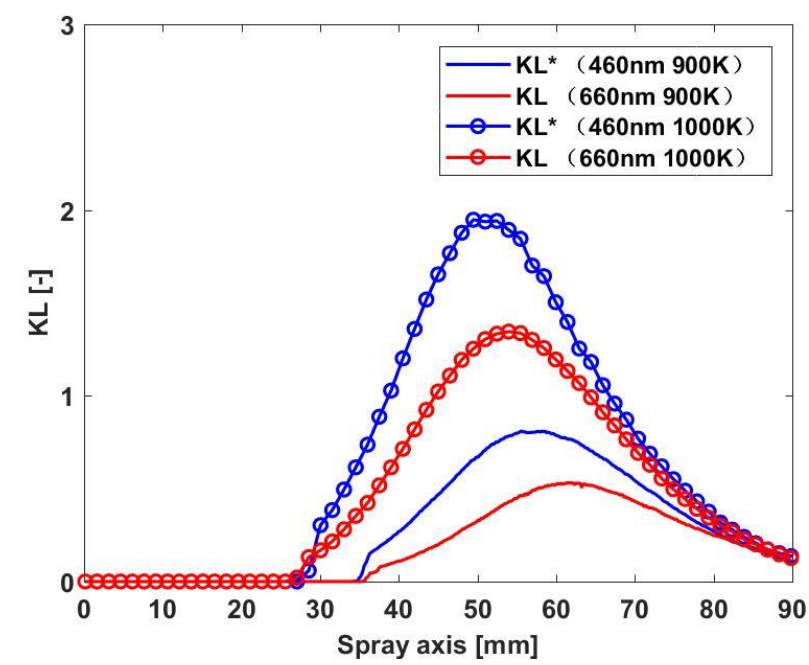

Fig. 9 Comparison of axial KL value derived from time-averaged KL map under two ambient temperatures. The blue one was converted based on Eq.(8). ( $\left.P_{i n j}=1500 \mathrm{bar}, \rho_{g}=22.8 \mathrm{~kg} / \mathrm{m}^{3},\left[\mathrm{O}_{2}\right]=15 \%\right)$.

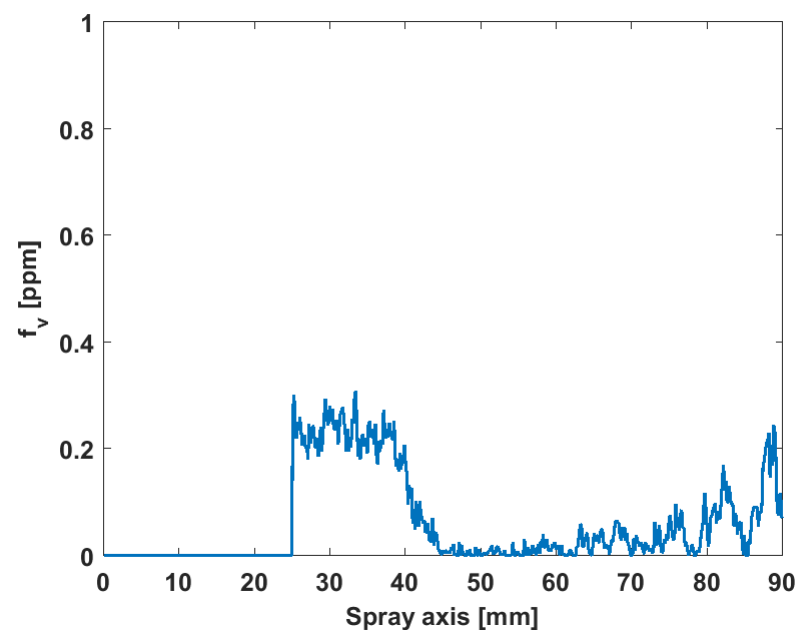

Fig. 10 Soot volume fraction along spray axis from time-averaged results ( $P_{i n j}=1500 \mathrm{bar}, \rho_{g}=22.8 \mathrm{~kg} / \mathrm{m}^{3}, T_{g}=800 \mathrm{~K}$, $\left.\left[\mathrm{O}_{2}\right]=15 \%\right)$.
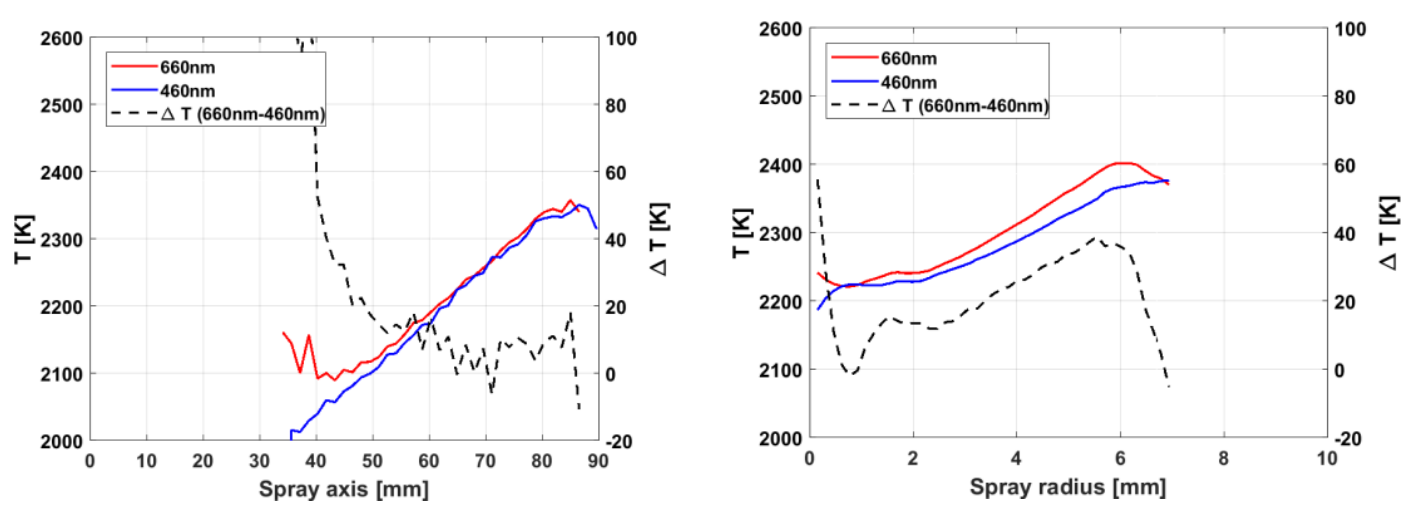

Fig. 11 Axial temperature distribution at $1 \mathrm{~mm}$ away from spray axis (left) and Radial temperature distribution at $65 \mathrm{~mm}$ (right) from different extinction wavelengths . ( $P_{i n j}=1500 \mathrm{bar}, \rho_{g}=22.8 \mathrm{~kg} / \mathrm{m}^{3}, T_{g}=1000 \mathrm{~K},\left[0_{2}\right]=15 \%$ ). 


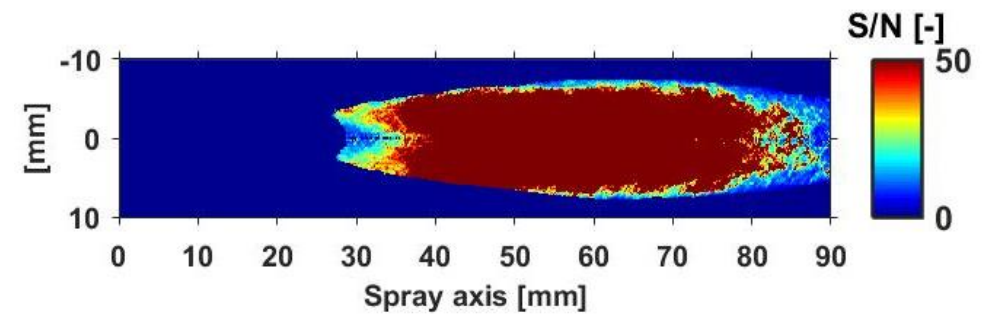

Fig. 12 Signal-to-noise ratio map with extinction wavelength $660 \mathrm{~nm}$ and radiation wavelength $660 \mathrm{~nm}\left(P_{\text {inj }}=1500 \mathrm{bar}\right.$, $\left.\rho_{g}=22.8 \mathrm{~kg} / \mathrm{m}^{3}, T_{g}=1000 \mathrm{~K},\left[\mathrm{O}_{2}\right]=15 \%\right)$.
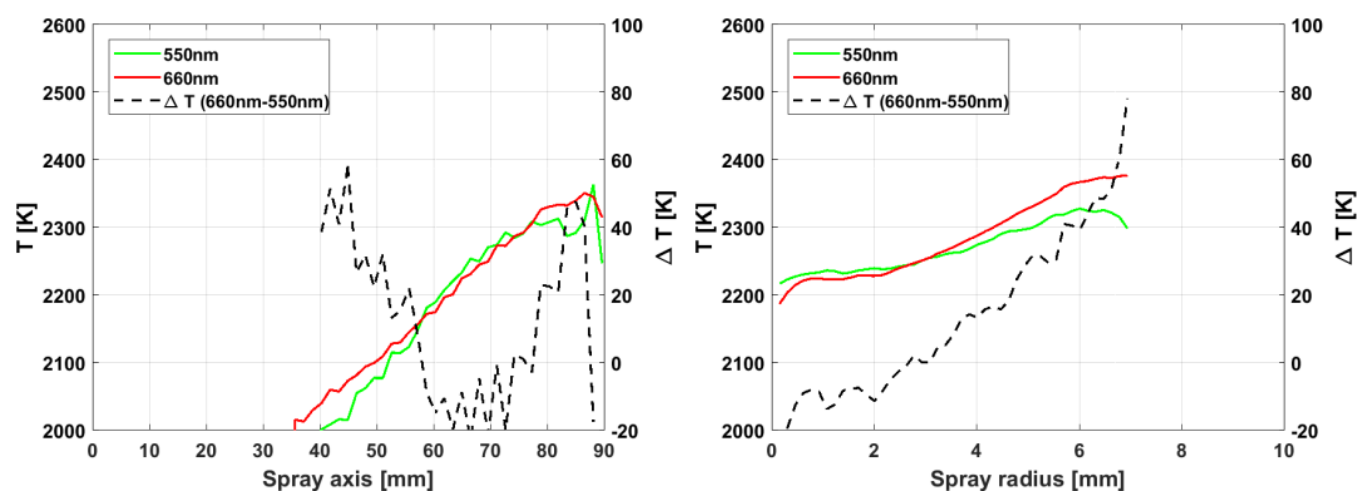

Fig. 13 Axial temperature distribution at $1 \mathrm{~mm}$ away from spray axis (left) and Radial temperature distribution at 65 $\mathrm{mm}$ (right) from different radiation wavelengths. ( $P_{i n j}=1500 \mathrm{bar}, \rho_{g}=22.8 \mathrm{~kg} / \mathrm{m}^{3}, T_{g}=1000 \mathrm{~K},\left[\mathrm{O}_{2}\right]=15 \%$ ).

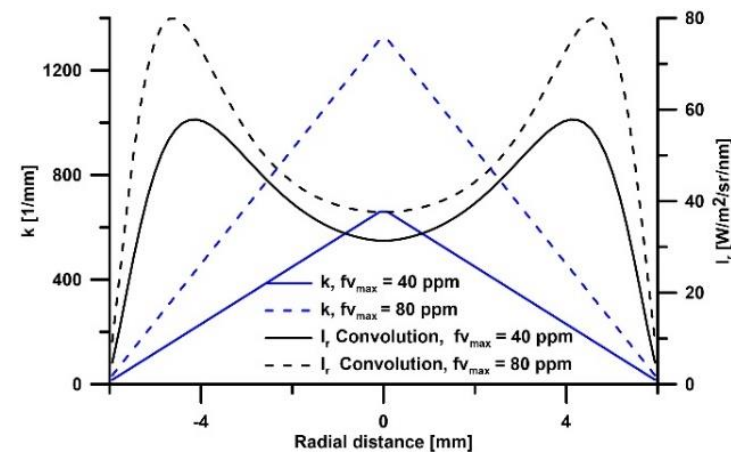

(a)

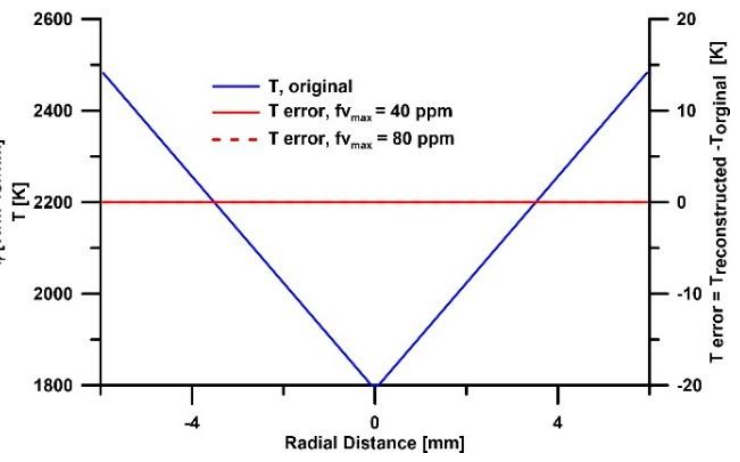

(b)

Fig. 14 Assumed radial profiles of $k$ on spray symmetric plane and projected radiation intensity $I_{r}(a)$ assumed and reconstructed soot temperature radial profiles on spray symmetric plane (b) .
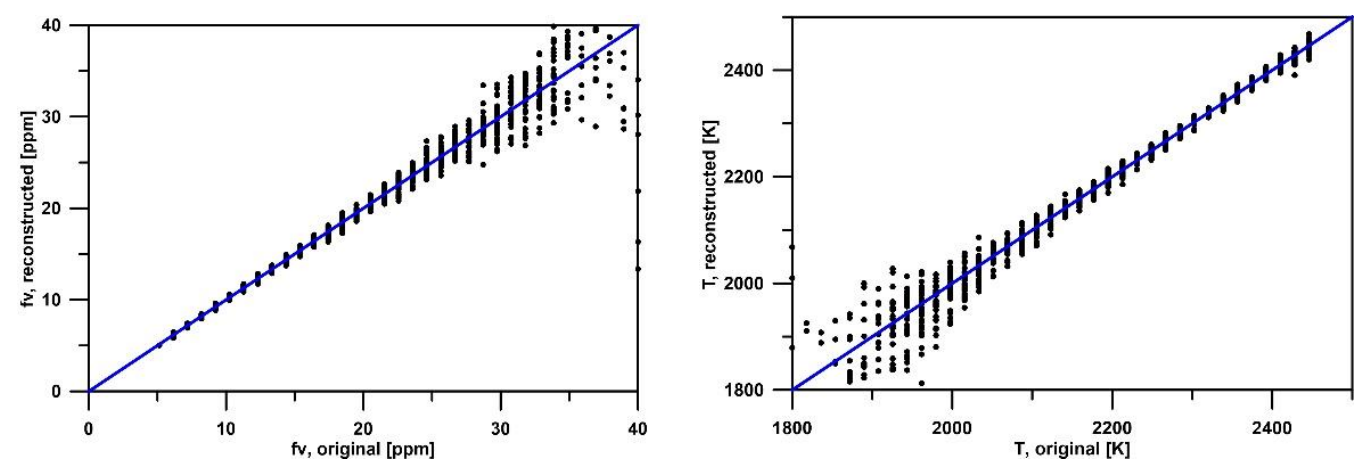

Fig. 15 Reconstructed soot volume fraction (left) and soot temperature (right) as function of original numerical input data. 


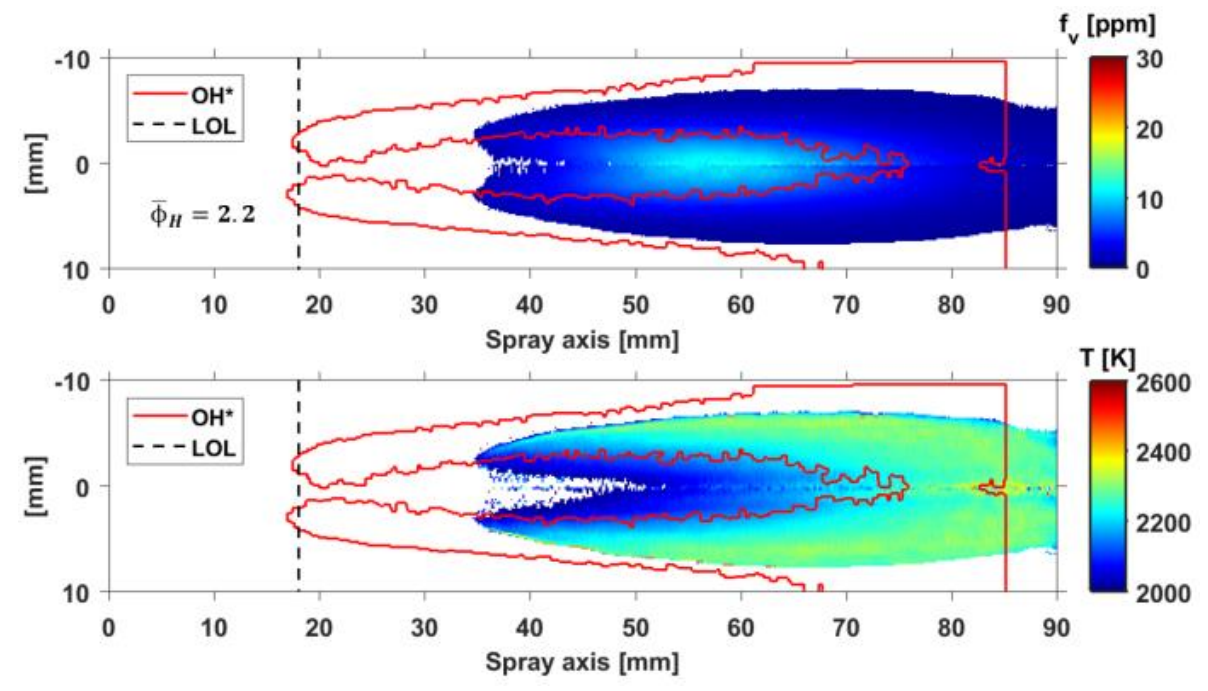

a. $\left(P_{i n j}=1500 \mathrm{bar}, \rho_{g}=22.8 \mathrm{~kg} / \mathrm{m}^{3}, T_{g}=900 \mathrm{~K},\left[\mathrm{O}_{2}\right]=15 \%\right)$.
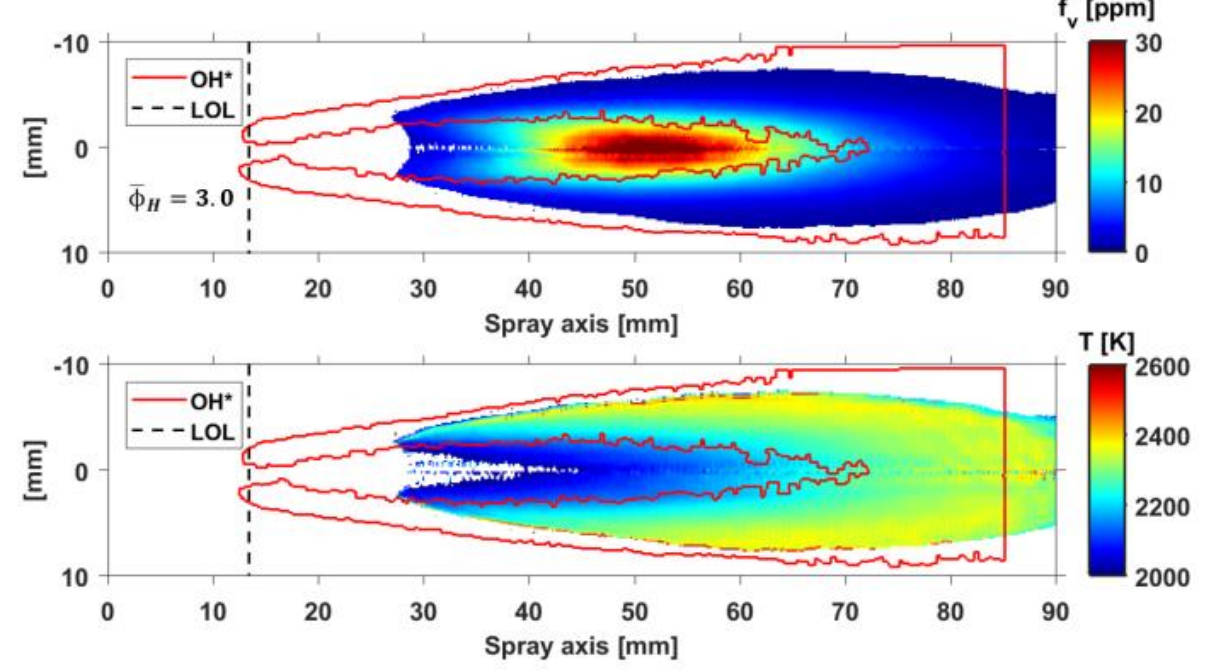

b. $\left(P_{i n j}=1500 \mathrm{bar}, \rho_{g}=22.8 \mathrm{~kg} / \mathrm{m}^{3}, T_{g}=1000 \mathrm{~K},\left[\mathrm{O}_{2}\right]=15 \%\right)$.

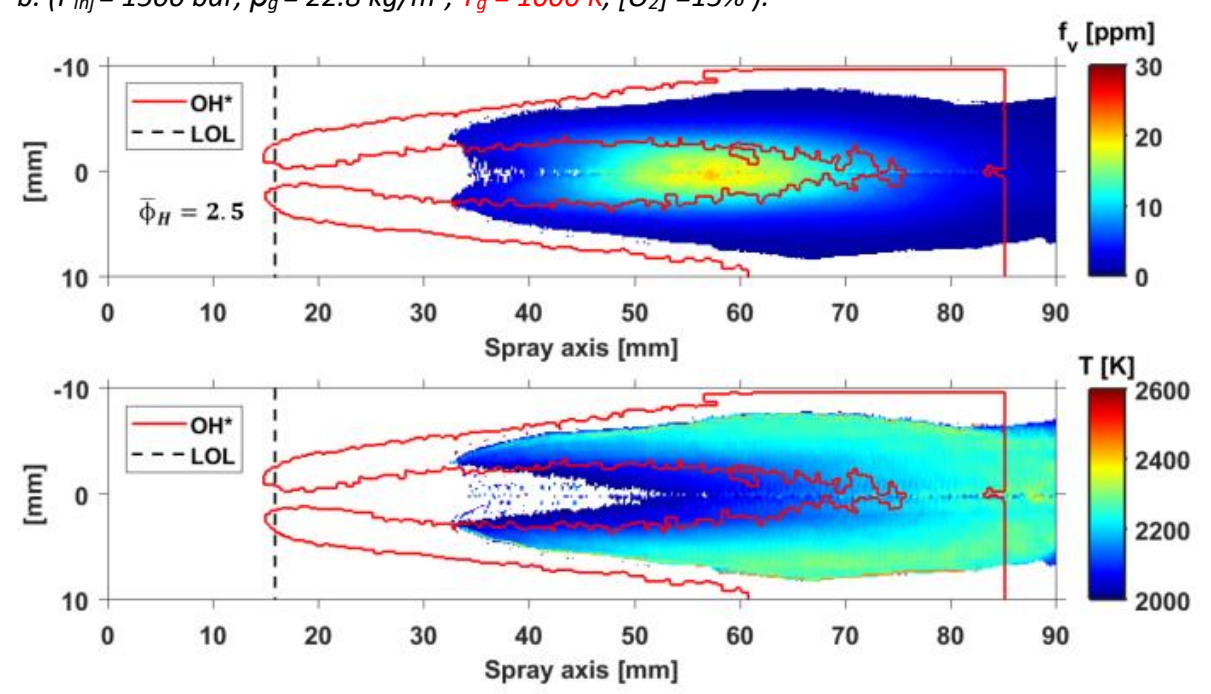

c. $\left(P_{\text {inj }}=1000 \mathrm{bar}, \rho_{g}=22.8 \mathrm{~kg} / \mathrm{m}^{3}, T_{g}=900 \mathrm{~K},\left[\mathrm{O}_{2}\right]=15 \%\right)$. 


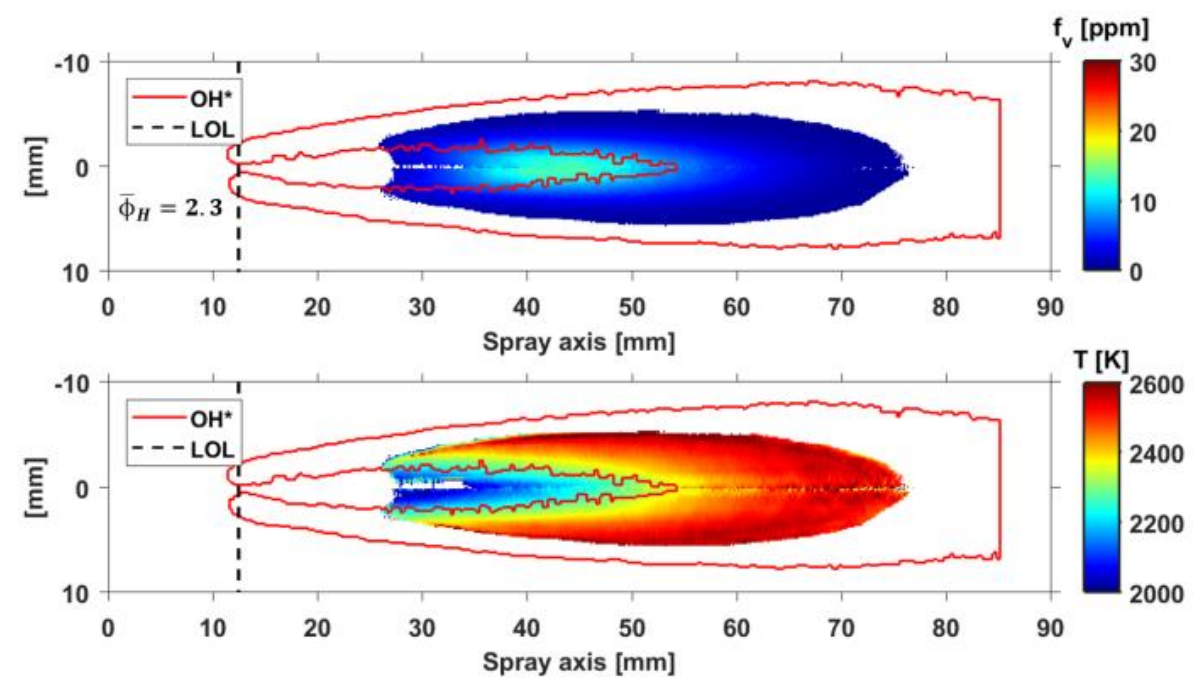

d. $\left(P_{i n j}=1500 \mathrm{bar}, \rho_{g}=22.8 \mathrm{~kg} / \mathrm{m}^{3}, T_{g}=900 \mathrm{~K},\left[\mathrm{O}_{2}\right]=21 \%\right)$.

Fig. 16 Soot volume fraction(fv) and Temperature(T) distribution on flame- axis plane reconstructed from LED KL map and radiation images. Vertical dashed lines represent flame lift-off length. Red curves represent $\mathrm{OH}^{*}$ contour

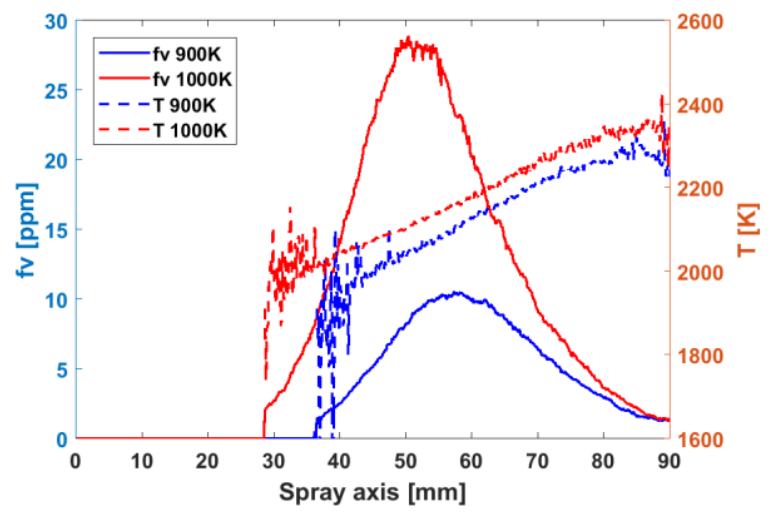

(a)

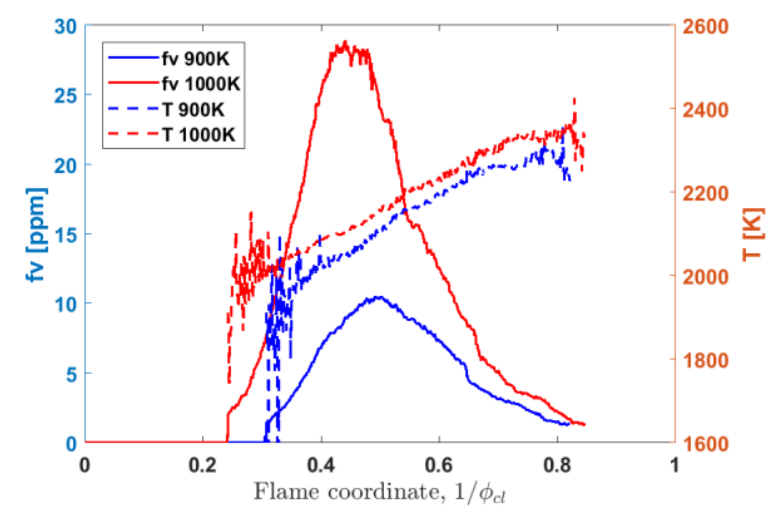

(b)

Fig. 17 Soot volume fraction and soot temperature along spray axis(a)and flame coordinate(b) with ambient temperature variation ( $\left.P_{i n j}=1500 \mathrm{bar}, \rho_{g}=22.8 \mathrm{~kg} / \mathrm{m}^{3},\left[\mathrm{O}_{2}\right]=15 \%\right)$.

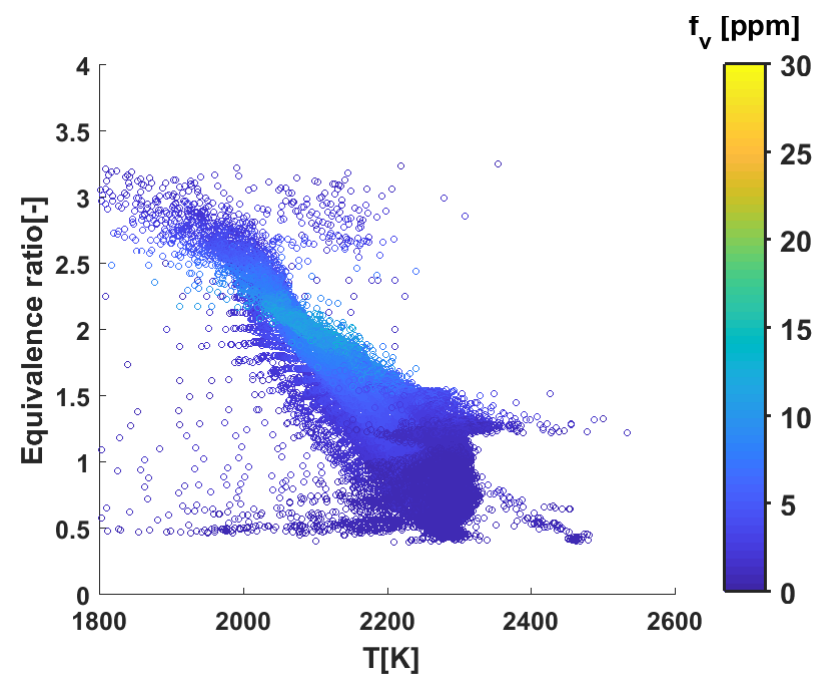

(a) $T=900 K$ 


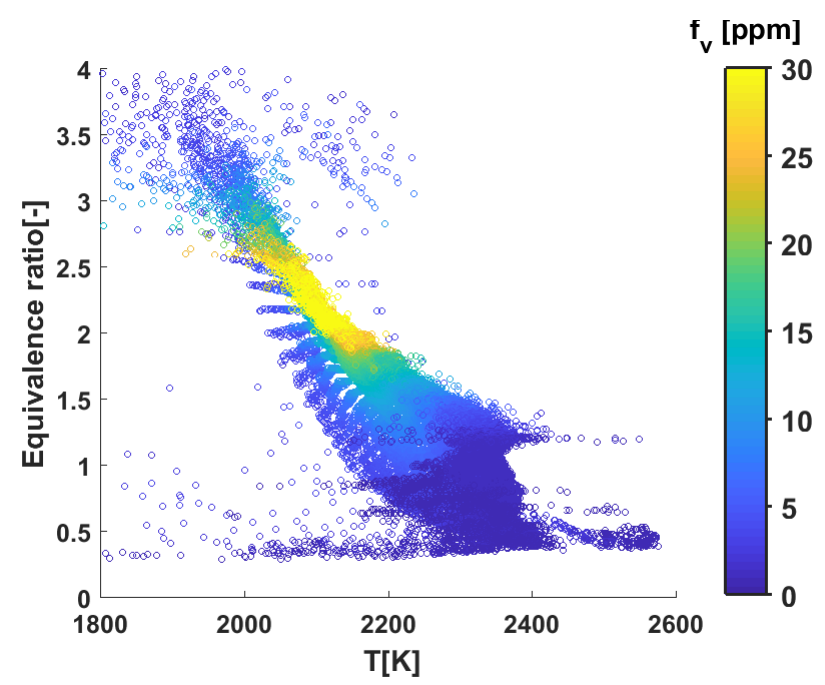

(b) $T=1000 \mathrm{~K}$

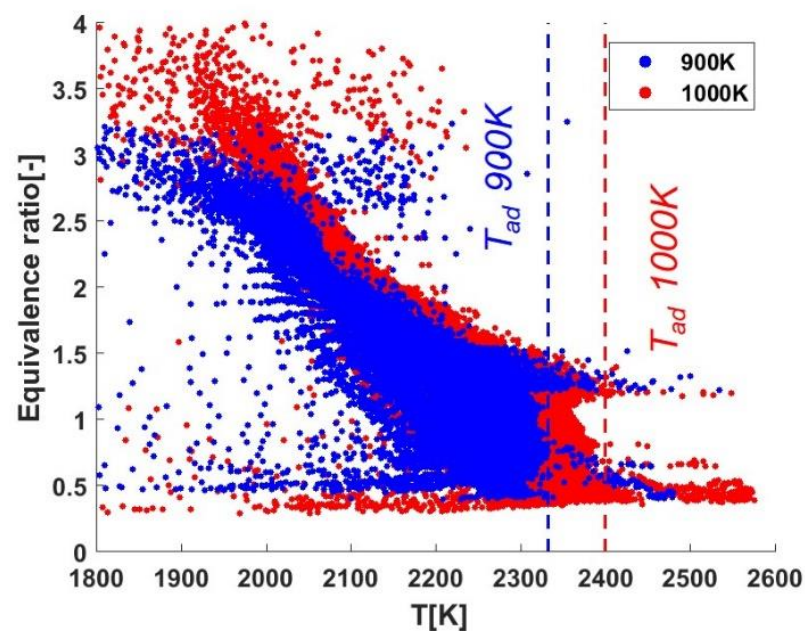

(c) soot relative distribution

Fig. $18 \phi$-T plots of two ambient temperature cases and their relative distribution. ( $P_{i n j}=1500 \mathrm{bar}, \rho_{g}=22.8 \mathrm{~kg} / \mathrm{m}^{3}$, $\left.\left[\mathrm{O}_{2}\right]=15 \%\right)$.

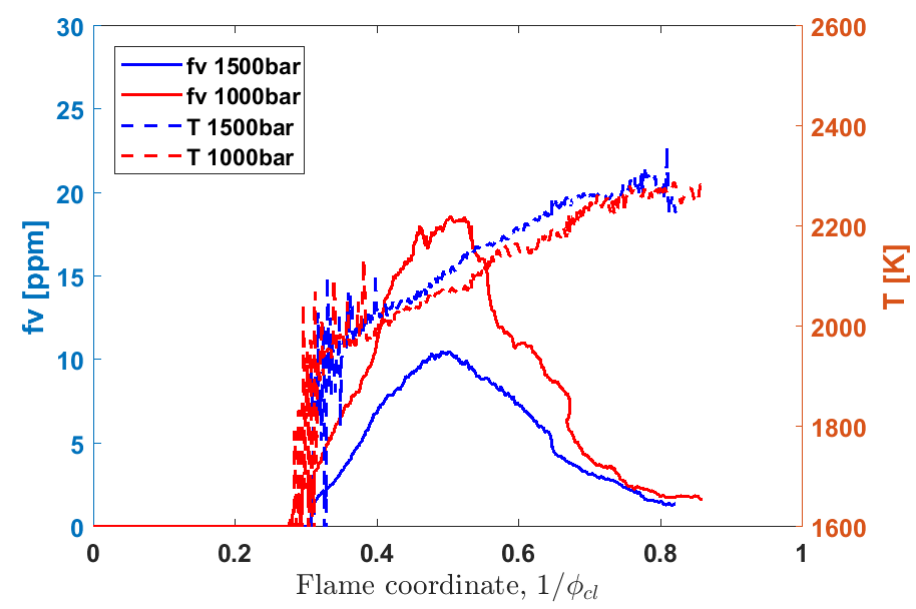

Fig. 19 Soot volume fraction and soot temperature along axial location of two injection pressure cases $\left(T_{g}=900 \mathrm{~K}, \rho_{g}=\right.$ $\left.22.8 \mathrm{~kg} / \mathrm{m}^{3},\left[\mathrm{O}_{2}\right]=15 \%\right)$. 


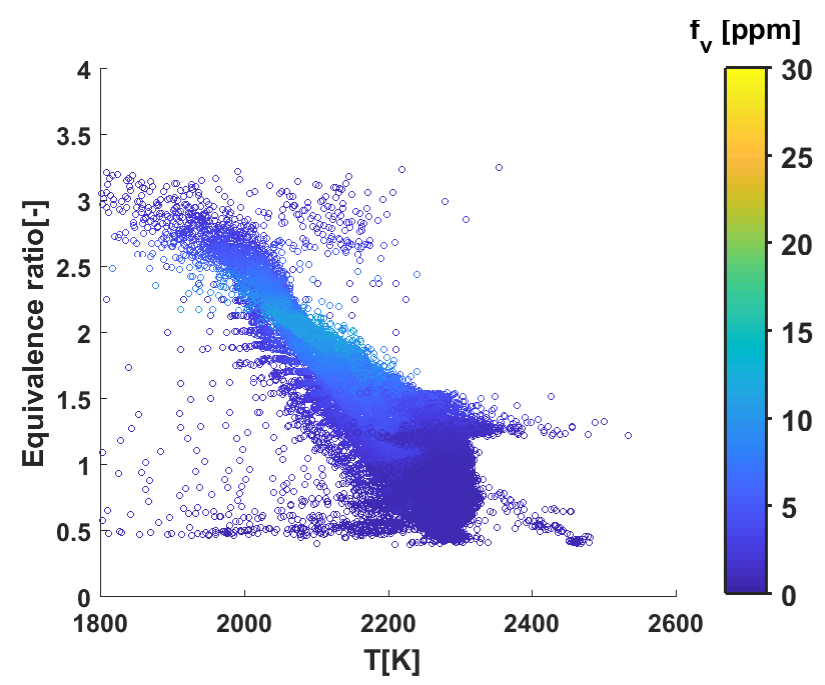

(a) $P_{\text {inj }}=1500 \mathrm{bar}$

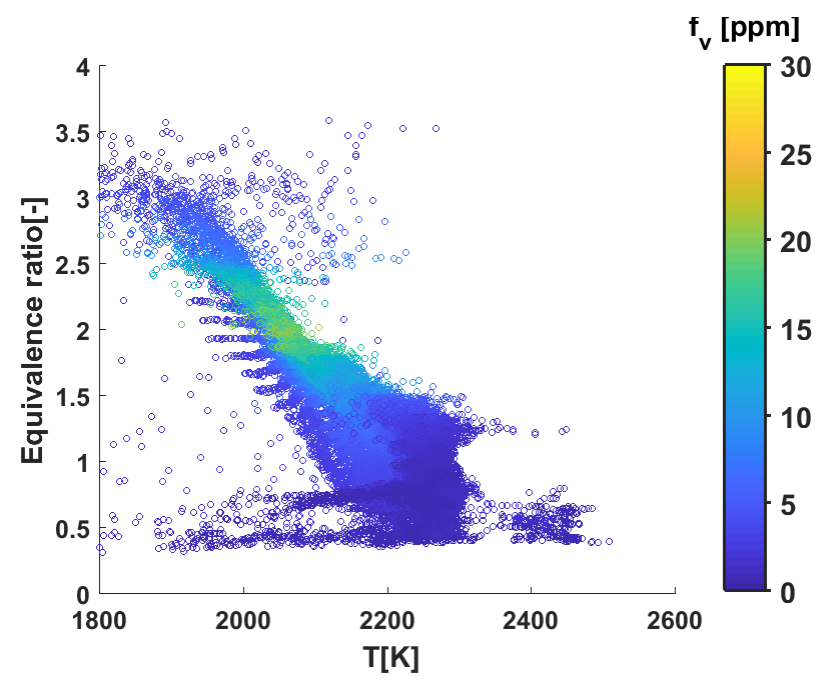

(b) $P_{i n j}=1000 \mathrm{bar}$

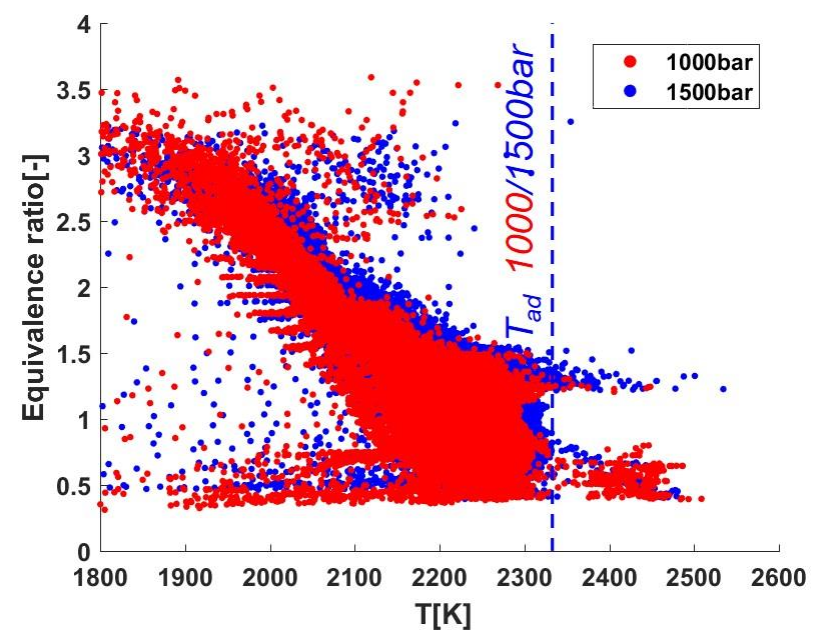

(c) soot relative distribution

Fig. $20 \phi$-T plots of two injection pressure cases and their relative distribution. . $\left(\mathrm{T}_{g}=900 \mathrm{~K}, \rho_{g}=22.8 \mathrm{~kg} / \mathrm{m}^{3},\left[\mathrm{O}_{2}\right]=\right.$ $15 \%)$. 


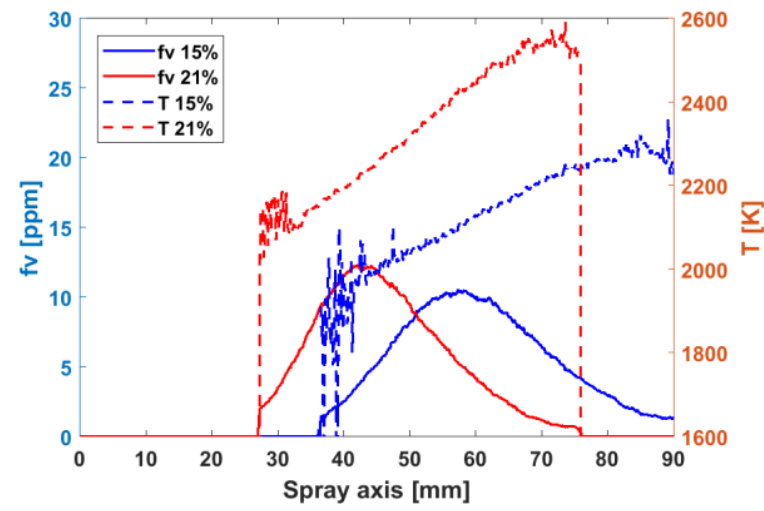

(a)

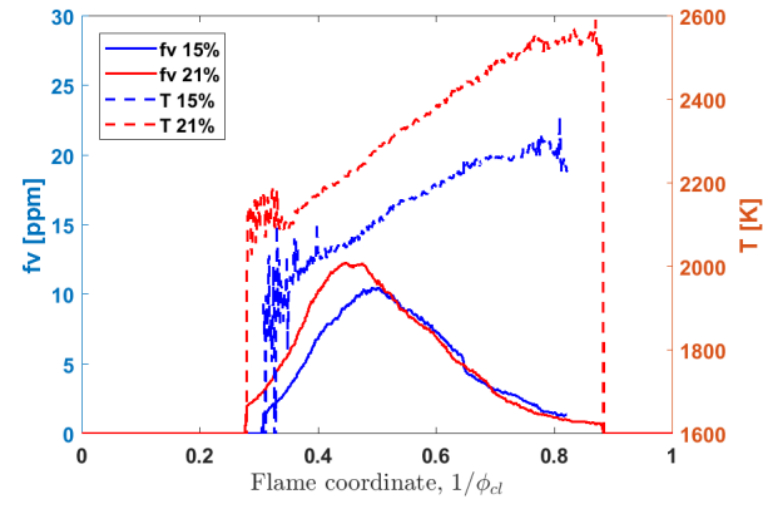

(b)

Fig. 21 Soot volume fraction and soot temperature distribution on the axis in physical (a) and flame coordinates(b). ( $P_{\text {inj }}$ $=1500 \mathrm{bar}, T_{g}=900 \mathrm{~K}, \rho_{g}=22.8 \mathrm{~kg} / \mathrm{m}^{3}$ ).

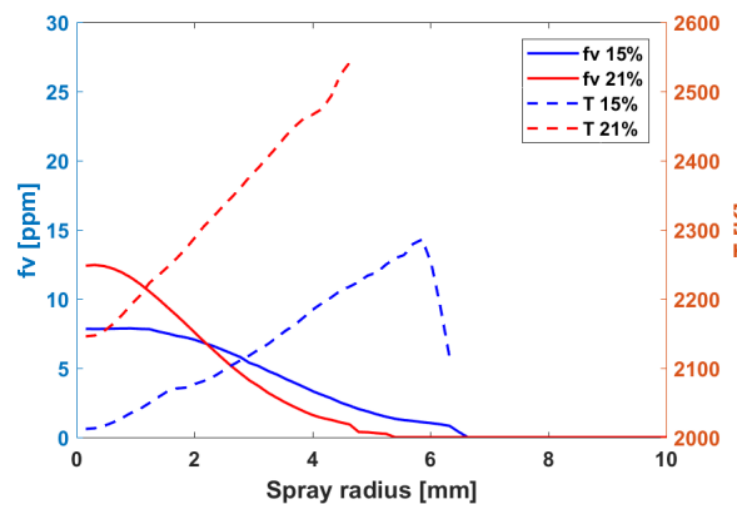

(a)

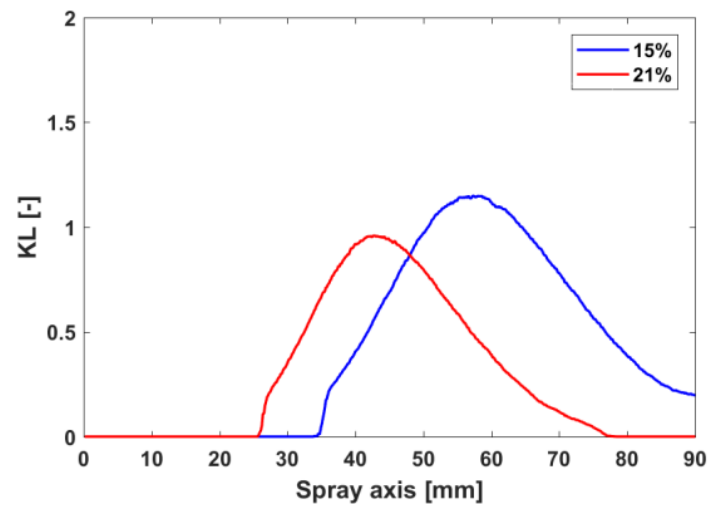

(b)

Fig. 22 spray radius at 0.42 flame coordinate (a) and KL along flame coordinate (b) with oxygen concentration variation $\left(P_{i n j}=1500 \mathrm{bar}, T_{g}=900 \mathrm{~K}, \rho_{g}=22.8 \mathrm{~kg} / \mathrm{m}^{3}\right)$.

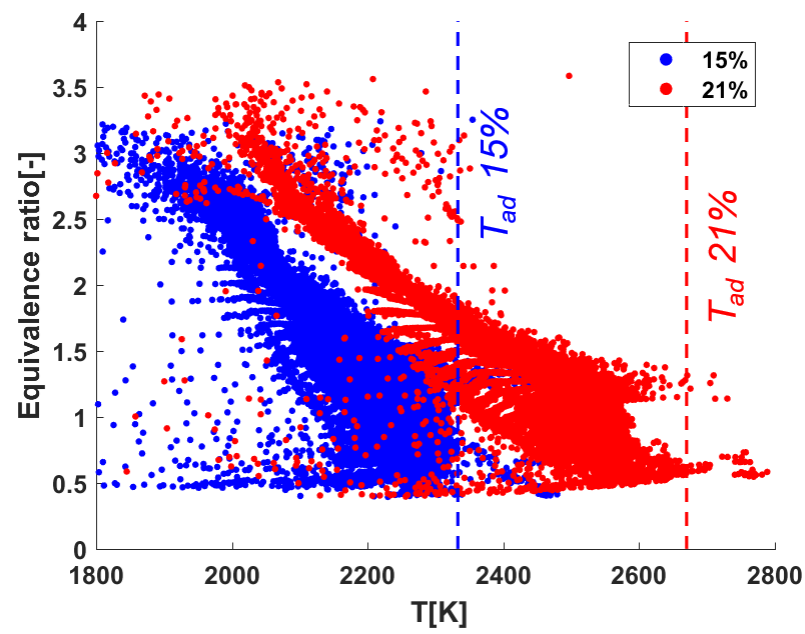

Fig. $23 \phi$-T plots location of two oxygen concentration cases ( $\left.P_{i n j}=1500 \mathrm{bar}, T_{g}=900 \mathrm{~K}, \rho_{g}=22.8 \mathrm{~kg} / \mathrm{m}^{3}\right)$. 